\title{
Line Managers' Devolution in Achieving Employee Engagement: Cracking the Code for Organizational Performance
}

\author{
Muhammad Zeeshan Khan \\ Department of Management Science, Fast National University \\ Karachi, Pakistan \\ Email: zeeshan.khan@nu.edu.pk
}

Received: August 06, 2016 Accepted: December 04, 2016 Published: December 28, 2016

doi:10.5296/ijhrs.v6i4.10563 URL: http://dx.doi.org/10.5296/ijhrs.v6i4.10563

\begin{abstract}
In this era of economic downturn, corporate and organizational progress does not necessarily translates into human and people development and thus due to the past decades, there is a growing competition all over the world and every business organization is seeking for ways on how to compete successfully in such an environment and this apparently would induce the corporate world to jump at the opportunity to promote productivity within an organization. In this context, the research discovered the need of the most significant and contemporary practice of organization called "Employee Engagement" that could easily foster organizational performance in the long run. Seen in this light, this piece of research identifies the root causes of engagement issues and processes. To put it in other way, this study significantly examines what the employees aspire in order to get involved and engaged within their job roles and also think about the implications of addressing the factors that Line Managers' should espoused to enhance engagement in order to improve organizational performance. In fact, the primary research findings indicated the lack of engagement processes among employees within the firm and exhibit the importance of promoting pay, recognition, autonomy, social support, and relationships, transparent methods of recruitment $\&$ selection, and flexible work hours to engage employees.
\end{abstract}

Keywords: Engagement; Line Managers; Organizational Performance; Barclays Bank. 


\section{Introduction}

"The year 2009 dawned screaming like a hydra-headed economic monster taking no prisoners" (Wallace \& Trinka, 2009). Research indicates that local governments and corporate world "polishing budgets to cover shortfalls, postponing major investments, hosting angry citizen meetings and even restructuring the organizations" in terms of strategic financial moves (Wallace \& Trinka, 2009). This is happening due to the fact that economic and organizational progress doesn't necessarily translate in to human and people development and thus during the past decades, there is an increasing competition all over the world and every organization is seeking the ways on how to compete successfully in such an environment.

This period of crucial challenge would make the organization jump at the opportunity to come up with productivity within organizations. In this perspective, the research identifies that engaged employees enhance organizational productivity.(Wallace \& Trinka, 2009). But what drives this engagement? Line management is important than any other organizational variable. Greater line management stimulates high levels of employee engagement that drive organizational performance (Wallace \& Trinka, 2009). Seen in this light, this management report aims to address the line managers' implications to enhance employee engagement processes and its impact on organizational performance. In particular, the focus of this research is to gauge the areas or identify the factors, which line managers should espoused to work on improvements to alleviate the disengagement levels and the business operate more effectively and efficiently (Baumruk, 2006).

Employee engagement is an issue for numerous companies as many managers confronting issues in order to be prevented from disengagement levels (McBain, 2007). This problem has also been prominent at Barclays bank, where disengagement among employees affecting organizational performance in the long run.

Since, research has recognized that 'line managers probably have greatest impact on engagement', (Mcbain, 2007) so this report will first identify that how employee engagement could be improved within a firm and to explore line managers' interventions to reduce disengagement among employees; secondly to devise employee engagement strategies or factors and how it improves organizational performance and to recommend how line managers within an organization can support and influence the changes.

To address these issues and practices the report would first consider the academic views in the form of literature review for subsequent analysis. Secondly the report would explore the research methods and approaches. Thirdly, the report would then explain research findings, analysis, and discussions in detail. Ultimately, from this examination of data, conclusions and recommendations would be drawn.

\section{Literature Review}

\subsection{Engagement: A closer look}

Engagement at work was first introduced by (Kahn, 1990) as delivering or harnessing the 
employee efforts towards their work roles. In engagement people within the organization express themselves physically, cognitively and emotionally attached during their job roles (Luthans \& Peterson, 2002) offered (Kahn's, 1990) work on personal engagement illustrated that to be emotionally engaged is a meaningful connection to others such as connection or relationships between peers, co-workers, employers and employees and to express empathy, which means feel what others feel (Bhatnagar, 2007). However, to be cognitively engaged refers to those, the employees 'who are aware of their vision and mission' within the organization (Bhatnagar, 2007). In connection to the above mentioned definitions, cognitive engagement consists of two factors "absorption and attention" (Rothbard, 2001). Absorption proposes the substance of focus, which an employee exhibits during his job (Ho \& Wong, 2008). To put it simply, absorption describes the intensity of employees to work, who are deeply involved in their work. Whereas attention pertains to the amount of cognitive resources, including concentration and energy, that an individual within the firm shows (Gardener \& Dunham, et al, 1998). Perhaps a more relevant definition comes from (Hewitt \& Associates, 2004) that employee engagement is "a measure of the energy and passion, which employees have for their organization. Engaged employees are the individuals who intends to improve business of an organization. They stay, say and strive-stay within the organization and say positive things about workplace and strive to go above and beyond to deliver extra ordinary work."

On the contrary, (Schaufeli \& Bakker, 2004) defined engagement in a bit different way they stated that a "positive, fulfilling and work related state of mind that is characterized by vigour and dedication (Schaufeli \& Bakker, 2004, p.295). Vigour is described as high level of energy and mental resilience at work, which depicts the ability to absorb shocks and be persistent at the time of adversity. Whereas, dedication refers to the sense of importance to the organization in terms of taking pride and challenge at work (Schaufeli \& Bakker, 2004, p.295). Employee engagement is also viewed as the opposite of job burnout (Laschinger \& Wilk, 2009) the occurrences, which are the results of heavy job demands in inadequate or less resources and has been linked to positive psychological conditions contingent on intrinsic (recognition and praise) and extrinsic (rewards and benefits) motivation, which could improve work effectiveness (Laschinger \& Wilk, 2009).

Linking these above aspects with (Kahn, 1990) work. He, however, agrees in his definition that employee engagement is based on three psychological conditions at work place, which are "meaningfulness, psychological safety and availability". Meaningfulness illustrates the intrinsic and extrinsic values of employees, which are associated to performance outcomes within the employees work roles (May, et al, 2004). Besides that, an intrinsic and extrinsic value of employees is a key concept in employer branding, which is beneficial and critical in attracting and engaging employees within the organization (Minchington, 2005). On the other hand, psychological safety entails the freedom, one feels at the workplace, which is quite significant factor to have interpersonal interaction with peer and co-workers at the workplace (May, et al, 2004). Ultimately, availability depicts that employees own the psychological states such as physical, cognitive and emotional resources, so that they could cascade these resources within their job roles (May, et al, 2004). Finally these three conditions determine 
the engagement and disengagement at work (Kahn, 1990). According to (Gallup, 2009) postulated in the academic literature of (Schmidt et al, 1993) argued that employee engagement is the notion of "involvement, commitment and satisfaction at work" this integrates classic construct of job satisfaction and organizational commitment (Meyer \& Allen, 1991). However it is argued that engagement is different from satisfaction as (Gubman, 2004, p.43) expounded that engagement is "a heightened emotional connection to a job and organization that goes beyond satisfaction" that enable employees to perform better and make the workers stay and strive longer and also make them feel socially accepted and recognised in their jobs (Lockwood, 2007).

Despite its conceptual overlap or distinctions between the theoretical terms, such as organizational commitment, job involvement and satisfaction, evidence suggests that engagement is entirely different from these terms (Hallberg \& Schaufeli, 2006). It is further argued that "unfortunately, the terminologies is confused by the interchangeably use of the labels of engagement, involvement, satisfaction and commitment are different terms" (Schaufeli \& Hallberg, 2006). Job involvement is the phenomena, which exhibits dedication and enthusiasm to one's work whereas, commitment is being stated as the in depth attachment to one's job or work (Schaufeli \& Hallberg, 2006). In addition, (McBain, 2007) further argued in association with the overlaps of the terminologies, that engagement is seen as a positive attitude to the job and it is distinguished from both job satisfaction and commitment. 'It is more temporary and volatile than commitment, which is a more stable perception. Commitment and engagement are distinct but mutually influencing'. Engagement influences job satisfaction which in turn influences commitment. All three aspects, impact upon key outcomes recognised in the research (McBain, 2007). The research on current employee engagement practice suggests not mingling the terms commitment, engagement and job satisfaction. It could be possible for an employee to be highly engaged in his or her job but not committed to the firm and similarly to be committed to the organization, and want to remain with the organization, but not engaged to his or her job. However, high degree of either engagement or commitment should lead towards high degree of other, and vice versa (McBain, 2007). Moreover, engagement also intensifies job satisfaction, which in turn increases degree of commitment. The key here is to separate the elements in order to give a more clear understanding of what is actually going on. This would provide a better agenda for line managers to have meaningful association with the employees to improve better performance outcomes within the organization (McBain, 2007).

Likewise, (Gilson \& Harter, 2004) introduced a three dimensional concept of engagement, which is little bit different but there functions are more or less same (Schaufeli \& Salanova, 2002). Most specifically, (May, et al, 2004) distinguished between a physical component (e.g. "I exert a lot of energy performing my job"), an emotional component (e.g. "I really put my heart in to my job") and a cognitive component (e.g. "performing my job is so absorbing that I forget about everything else"), which are a bit similar to (Schaufeli \& Bakker's, 2004) dimensions of vigour and dedication respectively. However, (Falcon, 2006) stated that "engagement is the state of emotional and intellectual commitment to an organization or group. An engaged employee is a person who is fully involved in his or her work." 
Furthermore, (IES, 2008) described engagement as a positive attitude, which the employees have towards the firm and its values. An engaged employee knows the business context, and works with his fellows to enhance the business performance in the long run for the benefit of the organization.

At the same time, the challenge of engaging employees is escalating day by day (Pech \& Slade, 2006). However, there is a degree of uncertainty surrounding engagement and evidence suggests that the level of disengagement in real terms is questionable. According to a survey of 656 chief executives officers called from the countries all over the world, engaging employees is the fourth most significant management challenge (Avery \& McKay, 2007) "behind creating customer loyalty, managing mergers and alliances and reducing costs" (Wah, 1999). Further describing the importance of this challenge, the Gallup organization recently found that nearly $20 \%$ of US employees were engaged and an additional $54 \%$ were in the middle in their work roles (Fleming, et al, 2005). The authors calculated the cost of disengaged employees in US organizations is more than $\$ 300$ billion per year in lost productivity (Avery \& McKay, 2007). Moreover, the research was further enhanced by Gallup and Towers Perrin (Seijts \& Crim, 2006) suggests that employee disengagement is as problematic as in other countries. In fact, the latter found that only $14 \%$ of more than 85,000 employees across 16 countries were engaged (Aselstine \& Alletson, 2006). In addition, if we look at the research data on employee engagement, it clearly not an easy thing to achieve. In the report working life: Employee Attitudes and Engagement_ published in December 2006, the UK's Chartered Institute of Personnel Development found that only 35\% of the 2000 employees they interviewed were actively engaged with their work. A 2001 "Gallup survey in the UK revealed $19 \%$ engaged, $61 \%$ not engaged and $20 \%$ actively disengaged." I t is quite clear from the above findings that we are all paying the price of engagement gap (CIPD, 2006)

Now the question is who is responsible to pay the price of engagement gap? Who is going to make the significant contribution on organizational performance in terms of engagement and commitment? The answer to all the questions is "line manager" as (Ulrich \& Brockbank, 2005, p.71) stated that HR professionals have started to associate line managers in aligning with business outcomes and goals.... and 'moving from the practices themselves to ways to help the organization reach its business goals'.

\subsection{Examining the nature of link: Line Managers' Intervention in HRM}

In today's competitive world, the relationship between line managers, human resource management and development is being changing (Gibb, 2003) and becoming more focused as well (Budhwar, 2000). On the contrary, this relationship has also been stated doubtful by (Mankin, 2003) in terms of integration or connection between HRM and line managers. On the other hand, (Renwick, 2003) postulated that HRM is a "centre stage" role for line managers and there could be many reasons for this like decentralization, which have been cited as rightsizing, restructuring and an increased need to put emphasizes on employees inputs in order to improve organizational performance (Gibbs \& Renwick, 2003). In fact, line managers play a significant role in creating a positive influence on employee commitment 
and engagement and ultimately, business performance (Watson \& Maxwell, 2006) for e.g (Cunningham \& Hayman, p.9, 1999) emphasized the role of line managers in promoting an "integrative culture of employee management through line management". A recent report of (CIPD, 2006) indicates that line manager's intervention in various aspects of employee development such as coaching, communication, empowering employees, developing an organizational culture, work engagement and involvement has a positive impact on the overall organizational performance (Hutchinson \& Purcell, 2003). In addition, (Ulrich, 1998) and (Jackson \& Schuler, 2000) identifies that a partnership approach to HR need the connection of HR activities in to the work of line managers, which is quite significant in terms of engaging and involving employees within their job roles. However there is a potential bias in the literature, which have been identified by (McGovern, et al, 1997) that line managers responsibility for HRM is being problematic. The agenda here is the capability and keenness of line managers to perform HR tasks is somehow ambiguous (Bond \& Wise, 2003). Likewise, researchers have also investigated some disputes or controversies between line managers roles and HR responsibilities for e.g (Whitaker \& Marchington, 2003) argued that line managers performed insufficiencies in their ability and roles and a kind of disruption from managers focus and tensions between HR professionals expectations in association with completion of tasks. Besides all these paradoxes between HR department and line managers, it has been widely recognised that line managers have a very crucial impact on engagement as they create the "micro environment" in which the employee works (McBain, 2007).

\subsection{Line Managers' implication in Employee Engagement}

Line managers play a pivotal role in terms of enhancing or augmenting engagement within the organization (Piersol, 2007). The role of line managers in creating conditions under which the employees will offer "discretionary behaviour" would have a positive affect on organizational performance (CIPD, 2009). Discretionary effort or behaviour is another important term, which could be described as a "getting people to contribute more than their job strictly require of them (Mann, 2001). In connection to this point, how could line managers make the employees to contribute more? The answer is Communication, which is the important ingredient to promote discretionary behaviour and engagement (Piersol, 2007) and it is also valid to link organizational characteristics to employee attitudes and behaviour study (Oakley, 2004). "Communication has to flow up as well as down". According to James Oakley, author of the North western University study (cited in Terzo, 2005, p.19) "the organizations that are exemplary in the study are the ones that have a system set up that allows for information to flow from the front line employees to senior management, so the employees understand what's going on and feel like they are listened to." No employee could be engaged automatically, unless it is developed. It is the responsibility of line managers to develop the literacy programs for employees, so that they come to know the business of the organization and how the organization makes money. Most specifically, employees need to understand how they can contribute and "establish the line of sight" means that they should contribute to the organization in financial profits (Carney, 1999, p.7)

"The manager able to create a vivid line of sight from an employee's work to create critical organizational outcomes creates greater engagement” (Wallace \& Trinka, 2009). 
To be engaged, employees need to feel that they are valued partners, and in this respect, Communication makes employees feel valued by their managers, and the manager values employee's contribution. Enhanced employee engagement should in turn feel in to improved work performance, reduces staff turnover and make it easier to recruit good employees because the employer has a positive image. Line Managers within an organisation must be able to define how they involve people when developing the organisation business plan and when analysing team and individual objectives (CIPD, 2007)

According to CIPD Research (2007) the most important drivers of communication are:

- Having opportunities to feed upwards.

- Feeling well informed about what is happening in the organisation.

But in a study carried out in 2004 by CIPD "just 55\% of employees believed that they were being kept informed about what their company was doing, and only $65 \%$ felt that they were given enough information to do their jobs effectively so it's quite pervasive that there is still a long way to go before internal communication in many organisations can be said to be effective. In fact, line managers have a central role in communication development within an organisation."

According to (McKenna \& Beech, 1995, p.177) stated that communication is a process at the disposal of the organization to keep management and employees informed about a variety of relevant matters. For instance, it is important for line managers to let employees know about the goals and objectives of the company and they should also be informed that what is expected of them in terms of performance, and how it could change the strategic direction of the company, which is likely to affect employee engagement within the organization. Further more, "Good communication is the life blood of an organization", it helps to promote the involvement of employees in the decision making processes, and in so doing can enhance the individual's identification with the organization, which in turn can lead to improved business performance. Consequently, it could be stated that line managers have a unique role to play in communication, the direct relationship they have with employees. They should give them the opportunity to speak more openly and build on the relationship, which could affect work engagement (Pegg, 2009)

\subsubsection{Employee Selection}

Another manager's role and responsibility in the engagement context is employee selection. Many companies understand the importance of putting the best on individual characteristics and personality attributes when hiring. "Selecting employees for the right culture fit goes a long way to develop an engaged workforce" (Piersol, 2007). In addition, (Gubman, 2004, p.42) argued that if "engagement is an associated personal connection to the organization" research should focus on an individual rather than on other factors. 'Is it possible for someone to remain engaged in spite of a negative environment, a difficult job, or a poor boss'? And if so how can we find "permanently engaged" individuals. So this research focus on the personality traits of individuals that manager should seek to enhance engagement levels within the organization (Wildermuth \& Pauken, 2008). In addition, personality traits could 
matter individuals more likey to experience burnout are more anxious than average, and engaged individuals are more likely to be extroverted (Wildermuth \& Pauken, 2008)

The first three traits are.... Hardiness, locus of control, and coping style... were identified by (Maslach et al, 2001). Hardiness means openness to change, which managers should look when doing selection process. Hardiness means the ability to survive when "the going gets tough," In other words it is the resilience, which managers look for in employees. Internal locus of control means that the individuals are more likely to attribute events and achievements to their own abilities and efforts. Finally, individuals more likely to remain engaged have an active rather than passive coping style (Wildermuth \& Pauken, 2008).

Self esteem is another trait that positively impacts engagement. Indeed, (Janssen et al, 1999) found that individuals with high self esteem are less likely to become tired and exhausted. In other words self esteem allowed individuals to see situations more positively (Janssen et al, 1999) admitted, however, it is still vague that self esteem whether a cause or result of engagement. After all, line managers should be kept aware of this trait of individuals when they do selection processes in order to boost engagement within the organization. Further research is needed to explore more deeply the relationship between self esteem and engagement (Janssen et al, 1999).

Recently personality attributes are interconnected with both burnout and engagement (Langelaan et al, 2006) investigated that burned out employees usually have high "Neuroticism" (a correlated set of traits that includes pessimism, anxiety, worry, and other negative emotions). Conversely, engaged employees score low in neuroticism and higher in extraversion. In addition, extraversion is interrelated with enthusiasm, outgoingness, and a feeling of "take charge" (Howard \& Howard, 2001). Consequently, it could be commented that line managers should be cautious in doing selection processes, keeping in mind all the personality traits that could prove to be positive and supportive in increasing employee engagement within the firm. (Wildermuth \& Pauken, 2008).

\subsubsection{Employee Empowerment}

(David \& Myers, 1993) points out that "study after study finds that when employees have more control when they can help define their own goals and hours and when they participate in decision making their job satisfaction rises." He quotes the case of Herman Miller, the American Office Furniture Manufacturer and in 1989 one of the fortune Magazine's top 10 most admired companies, whose investment in employee empowerment was rapid with a 25-times increase in stock value between 1970, when it went public, and 1991.

In connection with the above mentioned literature, it could be suggested that to be truly engaged within the job, employees need to be empowered. They need to be feel trusted once they know the goals of the company, they need to understand that they are expected to make appropriate decisions within the organization in such a case 'line managers' must be aware of the role of empowering employees in order to promote work engagement processes and differential effects on the company as well as on financial profits (CIPD, 2007). Workplace empowerment and employee engagement as strategies for increasing job satisfaction and 
performance have received considerable attention in the general management literature (Laschinger, et al, 2006). Management researchers argue that empowerment is a powerful mechanism in increasing employee involvement in organizational activities that invariably intensifies job satisfaction and increased organizational productivity (Kirkman \& Rosen, 1999).

Using a participative leadership style by line managers is a feature of empowering people within an organisation. A positive relationship has been established between participation, satisfaction, motivation, quality, productivity, and business performance (Hollander \& Offerman, 1990) found that "empowered employees have a sense of ownership, responsibility, and satisfaction in their accomplishments, a sense of control over what and how things are done, and the knowledge that is important to the organisation, which leads towards employee engagement and organizational performance (Gervase, et al, 1996) "In a study of empowerment report increased productivity and efficiency, measured by increased customer satisfaction and innovation. Empowerment, however, doesn't always enhance work performance." (Wall et al, 2002). "Empowerment is likely to be more effective when there is a high degree of operational uncertainty when work processes are more predictable and understood." On the other hand, (Bass, 1998) suggests that, "if a person's goals are not aligned with the organisation then through being empowered, he or she may pursue self interest at the expense of the organisation." Besides that, (Alan Randolph, 1995) revealed that, "to avoid this, more rather than less structured is needed in empowered teams."

Empowerment nevertheless can enhance work engagement and organisational performance. (Lawler, et al, 1992) "reports a greater return on sales when employees are given more control and responsibility by their immediate managers. In fact, employees who are more empowered are later perceived as more innovative, influential, upwards, and inspirational." (Spreitzer et al, 1999),

\subsubsection{Concept of Mutuality}

As I have described above, that engagement could only be enhanced between line managers and subordinates unless there are mutually respected, recognised and move towards a shared and common goal and in this perspective, the paradigm of mutality could play a unique role in terms of engaging and involving employees to produce better financial outcomes.

Mutuality is defined by Henson (1997) "as experienced performed by each with respect to the other- reciprocal; having the same relation each toward the other, having in common-shared, and an organisation in which there are no stockholders- profits, losses, and expenses are shared". The derivation of the word mutual is mutated or change. Several synonyms for mutuality include give and take, sense of belonging equally to, collaboration and common goal (Kochan and Osterman, 2001) "At work place level these include teamwork, employee involvement in problem solving and a climate of trust. At functional level the principals involve employment security, investment in training and contingent compensation that reinforces commitment and participation. In essence, mutuality can be exhibited significantly as a connection or understanding of one another that facilitates a dynamic process of joint exchange between line managers and subordinates within an 
organisation. In fact, it is a sense of moving towards a common goal, most specifically, Mutuality precedes attainment of a common goal that is satisfactory. Ehringer (1991) suggested "that an ethic of mutuality embraces both care and justice. It offers the potential for ameliorating the conflict between altruism and individualism, and posits a new integration in fact, in a connected world, we cannot escape relatedness."

Consequently, managers and employees yield mutual gains in order to make the best effort and practice towards organisational performance. "It requires a package of measures involving innovative forms of participation and representation. In fact, it does no harm to the economic performance of the company and more likely, achieves commitment and engagement, which has been suggested by the theory." Metcalf, (2001).

\subsubsection{Rewards Management}

Another important factor of gauging employee engagement within the organization is rewards and benefits, which are the most, underutilized and mishandled managerial component for driving organisational performance. Armstrong (2008) suggested that "it must reward short as well as long term achievements, bearing in mind that business must perform in the present to succeed in the future." Reward systems can influence a number of HR processes and practices, which in turn impact on organisational engagement and commitment (Lawler, 2000).

Rewards influence engagement and retention. High wages attract more applicants; in addition, better performers generally need to be rewarded more highly than poor performers so performance based system are more likely to attract high performers (Lawler, 2000)

(CIPD, 2009) stated that HR focuses on rewards management [policies and procedures between line managers and subordinates in order to come up with better business outcomes. The aim of reward strategy is to attract, retain, and engage employees so that they can put their discretionary effort within their job roles (CIPD, 2009) also revealed that individuals are attracted by a range of financial and non financial rewards. However, a reward strategy is not going to be effective, unless the organization has the ability to execute it appropriately (CIPD, 2009) further revealed that in the annual reward management survey, the problems which were confronted by organization in implementing it, are the skills and the abilities of line managers to actually implement the strategy (CIPD, 2009). On the contrary, non-financial rewards such as recognition, praise, and feeling of being trusted within the organization are definitely crucial in increasing employee engagement. As it is stated by (Baumruk \& Gorman, 2006) that it is important for line managers to constantly recognize the employees for their performance and this could be in terms of thank you or congratulations, "all the way up to allocating organizational awards and bonuses". Indeed, recognition has a huge impact on engagement (Baumruk \& Gorman, 2006). In addition, accountability is also aligned with rewards strategy (Ulrich \& Brockbank, 2009, p.41) they further postulated that some 'organizations have developed accountability habits. Performance accountability becomes a firm capability when employees realize that they must meet their performance expectations'. Accountability comes when firm strategies interpret in to considerable benchmarks of performance and when rewards are linked in to those benchmarks of performance. 'When 
there is line of sight between rewards and strategies likely to follow' (Ulrich \& Brockbank, 2009, p.41). Furthermore, (Baumruk \& Gorman, 2006) suggested that employees are more engaged and likely to foster better performance outcomes, when their line managers effectively and efficiently embrace their team members accountable for results. An individual employee might do good work in a team where as the others might be lagging behind. If a manager could not do something to solve the problem or rectify the situation, that would lead towards disengagement (Baumruk \& Gorman, 2006). Similarly, line managers should be clear about anticipations of employees to ensure engagement. They need to be consistent in the harnessing the effects of those expectations. It is quite pervasive that managers need to be open to employees in terms of listening to their ideas and giving them constructive feedback on their performance levels.

\subsubsection{Social support}

Line managers should also focus on cooperation and team works, which are significant factors in order to accomplish organizational performance and social relationships with employees, is quite important in particular for individual engagement (Macey, et al, 2009, p. 125). He further proposed that this opportunity of social support gives employees to build on social relationships, which help the individuals in terms of relatedness to other co-workers and this apparently foster motivation and engagement to get connected with the other team members. In addition, this kind of social support can also increase the substance of psychological safety, which in turn reduces the degree of risk employees, when putting in the level of energy in their work (Macey, et al, 2009, p.125).

Most specifically, social networks are important in terms of interconnection between employees and line managers and this reinforces the component of knowledge transfer between line managers and employees. Moreover, it also enhances the information access and alleviates barriers that limit the information flow. Likewise, line managers interventions should also be made in enhancing intrinsic motivation of the employees, which can further equate with work engagement levels. In fact, they should be intrinsically motivated in the sense that they seek to find meaningfulness and pride in their work and feel dedicated and competent about their work. It could be further argued that we have invariably found the opportunity to use individual skills and abilities to be an important driver of employee engagement (Macey, et al, p. 126) so line managers' interventions "that serve to build confidence and resilience are those that help to enhance the motivation to engage (Macey, et al, 2009, p. 127).

\subsubsection{Line managers and employee relationships}

Employees who have interpersonal interactions with their co workers can experience greater meaning in their work (Gilson \& Harter, 2004). According to literature in organizational behaviour identified that relatedness is the need that every individual has (Locke \& Taylor, 1990). When employees are treated by their managers with "dignity, respect, and value for their contributions, they are likely to obtain a sense of meaningfulness and availability from their interactions." Consequently, it is therefore suggested that co workers interactions foster a sense of belonging, a great sense of social identity and meaningfulness will appear. In 
addition, line managers can also have a dramatic impact on an individual's perceptions of the psychological safety of a work environment. In fact, cooperation, support, and controlling relations of line managers and employees promote the essence of psychological safety, which is one of the significant variables of employee engagement (Edmondson, 1999) and also enhance the employee creativity on his job (Oldham \& Cummings, 1996). Line managers who display a cooperative and supportive work environment and show concerns for employees needs and feelings, provide positive feedback and encourage them to voice their concerns and solve work related problems would indeed enhance self determination, vigour, and dedication in their work (Deci \& Ryan, 1987). These employees are likely to feel safer within their work roles and could easily engage themselves in their job roles. Eventually, it could be proposed that the above mentioned aspects are quite significant to cultivate engagement levels, which can be learnt from each others behaviours when individuals are in such supportive environments (Edmondson, 1999).

Consequently, line managers supportiveness in augmenting employee's vigour, energy, and self determination in harmonious perceptions between line managers and employees have both linked with enhanced trust overall (Britt, 1999). Taken as a whole, this relationship of trust between managers and employees is expected to lead the feelings of psychological safety and a keenness to invest them at work.

\subsubsection{Work /life balance}

Work life balance is increasingly important to cultivate employee engagement within an organization (Richman, et al, 2008). In a nationally representative study of employees from mid to large companies, ability to manage the demands of work and personal life were strongly related to higher levels of employee engagement (Richman, 2006). Another studies also confirmed that, when employees have flexible work activities, they are likely to crop up with better mental health, resilience and dedication at work. In fact, line managers must offer the family friendly culture with the psychological conditions of meaningfulness (work role fit, job enrichment), safety (supportive relationship between line managers and co- workers), and availability (resources available) are more likely to have engaged employees (Lockwood, 2007). In addition, employees who worked for organizations that offered family friendly activities have a higher level of organizational commitment and lower intentions to leave (Richman, et al, 2006). Consequently, it could be suggested that line managers should arise engagement levels by promoting a culture of trust and relationships, respect and integrity, which could eliminate family stress and can enhance work engagement. Furthermore, an overall supportive workplace culture is significant in order to ensure flexible work/ life balance policies and procedures within an organization (Richman, et al, 2006). "Supportive supervisors or line managers have a positive effect on work and family matters as well as direct effects on psychological, physiological, and behavioural indicators of strain". Moreover, the availability of work/life balance programs and the distinct features of work family culture (time demands, manager support and sensitivity, and negative career consequences of devoting time to family) are integrated to the outcomes of organizational commitment, work family disputes, and intention to leave the organization (Thompson \& Lyness, 1999). Consequently, it could be suggested that an individual's flexible work 
schedule is a good fit to ensure engagement in the job role and it has also been shown a better predictor of employee engagement at work (Richman, et al, 2006).

\subsection{Summing up}

In today's corporate world companies cannot thrive unless their employees are engaged fully. Engaged employees- that is, employees who believe they are valued- share ideas, work harder than the necessary minimum, and relate better to customers (Heery \& Noon, 2008) cited in the (Dictionary of Human Resource Management, 2008, p.123) that "employee champion or employee advocacy involves representing the interest of employees within the management team and ensuring that there are equitable procedures governing the employment relationship. It is a role that may also encompass responsibility for health and safety, risk management and equality and diversity at work". In fact, in their new role, line managers must be held accountable for ensuring that employees are engaged - that they feel committed to the organization and contribute fully in order to intensify the business performance of the firm (Ulrich, 1998). Further more, commitment could be intensified by attending the social needs of employees for instance, picnics, and parties and so on. However, HR's new agenda supersedes them. HR should now take responsibility for directing and training line managers about the significance of high employee morale and engagement processes and how to achieve it. In addition, the contemporary HR should be the employees' voice in management decisions, offer social support, relationships, empowerment, and provide resources that help individuals meet the demands if all the factors which are described above integrated or collaborated together within the HR role and functions, then the employees would undoubtedly come up with better business performance within an organization (Ulrich, 1998).

\section{Methodology}

This study of "Employee Engagement" falls on exploratory and explanatory research in terms of its character so it sets off a bit forward comparatively with descriptive one and it focuses on the reasons that why certain phenomenon arises (Cooper \& Schindler, 2008).

\subsection{Research objectives and philosophy}

The research objectives of this report is to determine the extent to which line managers are pivotal in enhancing employee engagement in Barclays bank, and to make recommendations for best practice in order to improve organizational performance. The author has chosen to use an interpretive approach, which illustrates the complexity of human understanding, and find ways to explore the subjective meanings behind everyday beliefs and actions (saunders \& Thornhill, 2007), hence compatible for employee engagement studies. It is further proposed by (Veal, 2005) that interpretive paradigm sets on the assumption that "human behaviour is variable or changeable." This approach also reveals the different ways in which people view the world, and how this affects upon their investigation and understanding of the nature of the organizations (Burrell \& Morgan, 1979)

Furthermore, this research paradigm postulates that individuals influence their experiences in unpredictable means and causes of their motivational factors in accordance with this 
paradigm could be simplified by their feelings, thoughts, views and emotions. Consequently, this research report is based on how individuals act in an organization to come up with better engagement processes, which is a study of human behaviour and conducts research among social situations (Collis \& Hussey, 2009). Since, the nature of this study is subjective, the interpretive approach seems to be valid with this piece of study because it invariably integrates with the aims and objectives of the research.

On the other hand, there are two more major or foremost approaches, which are positivism and realism. Positivistic approach is contingent on the hypothesis that social reality is singular and objective and it cannot be changed by exploring or examining it. Just to put it simply, it is a proposition, which is not the result of any judgement and are discovered on the bases of observation and experience (Collis \& Hussey, 2009). In addition, it is also assumed that in the positivistic approach, human behaviour can be forecasted and thus recognises phenomena, which provides logical justification for it. Conversely, the positivistic approach is also confronting a paradox that it only guesses the average common behaviour not the individual behaviour, which seems to be drawback at times when individualistic understanding is needed. Another drawback with the approach is the hypothesis that is needed for the expansion of different models for prediction lead towards biases to the researcher (Cooper \& Schindler, 2008).

On the other hand, realism is the philosophy which describes that what "our mind or sense perceives is the truth". To put it in other words, it tends to exhibit that what exists outside and independent of human mind or sense is reality. There are two types of realism one is direct realism and the other one is critical realism. Direct realism tends to depict that what we visualize in our minds and what we perceive is the reality. In other words, what is seen and heard that gives knowledge and understanding is direct realism. In contrast, critical realism is the notion of what is experienced by the feelings or in other words what is seen and heard could be the hints of existing reality that is unseen and might be achieved by the sensations (Saunders \& Thornhill, 2008).

\subsection{Research Approaches}

In this management report of employee engagement, all the essentials of inductive and deductive approaches would be used. The deductive approach or method is aligned with the positivist theory which necessitates the development of theoretical structure before its testing through empirical observation (Gill \& Johnson, 2002). Likewise, it starts with the insubstantial conceptualization and then move towards testing the application of theory in order to come up with new studies, practices and experiences (Gill \& Johnson, 2002). It also involves clear rational thinking, that leads towards either in acceptance or rejection of a theory or question (Saunders \& Thornhill, 2007). In addition, there are some paradoxes or biases in line with this approach which have been proposed by (Saunders \& Thornhill, 2007) that it overlooks that people are thinking individuals and perceive or make inferences about the world in a different way from others. In other words, it could be argued that this method illustrates that individuals do not react to conditions or situations in the same way (Saunders \& Thornhill, 2007). 
Inductive research, however, is the opposite of deductive one that it moves from observation of empirical reality to the building of theories of what has been observed or examined (Gill \& Johnson, 2002). In connection to the point above, it could be argued that the inductive approach integrates with Kolb's learning cycle there by, learning by reflecting on past experiences and by originating the theories, knowledge and generalizations of past and with the help of those theories that were formulated before, it predicts the future experiences. However, there are some overlaps between induction and deduction approaches, in both natural and social sciences (Johnson \& Duberely, 2000). However, the contemporary explanation of inductive method has some potential biases. In fact, most of the researchers think that description of social phenomena is relatively useless unless, they are based in observation and experience (Gill \& Johnson, 2002). In fact, the most famous version of this view is postulated by (Glaser \& Strauss, 1967) that in contrast to deductive approach, the theory which is developed inductively is much more likely in terms of data validation and is more useful, credible and reasonable for practicing managers. Moreover, (Hyde, 2000) proposed that qualitative research actually follows inductive approach where as, quantitative research falls on deductive one. In addition, inductive method was build up in the social sciences context in order to encourage researchers to examine social and cultural study and it could be conducted in the form of surveys, questionnaires, interviews and observation (Gill \& Johnson, 2002).

To meet the objectives of this research, the mixture of both the inductive and deductive approaches would be compatible in accordance with the nature of argument. As (Hyde, 2000) suggested that many social scientists and researchers are now agreed to the view that both the qualitative and quantitative methods can be used for a valid research. Similarly, (Easterby Smith et al, 1991) proposed that many researchers who took up a mix of qualitative and quantitative approaches are a balanced proposition of any type of research. Hence, it is not a question of which method should be used for reasoning either induction or deduction sometimes both are required for research attempts and using any one of those could be objectionable (Hyde, 2000).

In order to meet the objectives of this research, it is ultimately proposed that the deduction approach enables the idea to be tested through a more structured methodology (Saunders et al. 2007). However, the inductive approach allows the author to gather qualitative data in order to gain in-depth knowledge, which is required to produce recommendations.

\subsection{Research Strategy}

This research would follow a case study approach, which is associated with interpretive philosophy and allow the researcher to focus on particular issue in a specific situation. According to (Saunders \& Thornhill, 2007) "a case study involves an empirical investigation of a particular conventional issue within its real life context". On the contrary, the phenomenon which is being studied is not clearly evident in this strategy.

(Morris \& Wood, 1991) proposed that case study strategy plays a pivotal role in terms of gathering critical insights and in depth understanding of the issue. Hence, in order to accomplish these research objectives, it would be a mixture of explanatory and exploratory 
researches and the data collection tactics would also be an amalgamation of qualitative and quantitative methods in order to get a better understanding of the argument. Like wise, it is argued that qualitative studies may be combined with quantitative in order to enhance the quality of the research (Cooper \& Schindler, 2008). Similarly, many researchers identified that "qualitative research compensates for the weaknesses of quantitative one and vice versa. They further suggested that methodologies complement rather than rival each other" (Saunders \& Thornhill, 2007). Further more, (Eisenhardth, 1989, p. 534) stated that it is usually best to combine the qualitative and quantitative approaches together and also to combine data collection methods such as interviews, questionnaires and observations. "The evidence may be qualitative and quantitative (e.g. numbers) or both." (Collis \& Hussey, 2008).

\subsection{Research Methods}

\subsubsection{Secondary Research}

This management research requires highly in depth knowledge of employee engagement processes, practices and propositions, which is aligned with the focus on line managers. In other words, the research question is how line managers could enhance employee engagement in order to improve organizational performance. It needs to review the existing literature on topics and journal articles in line with multinational companies such as Gallup and also the professional management bodies like CIPD (Certified institute of personnel development), IES (Institute of employment studies), ACAS and most specifically NORA. All these would prove to be significant in order to come up important and crucial sources of data on research question. In addition, various sources of books and journals would also be consulted in order to seek theories and practices of the issue, which could be fruitful in providing comprehensive information on the question.

\subsubsection{Primary Research}

This research of "Employee Engagement" would follow two different methods in order to seek the perfect picture of how line managers enhance engagement processes to improve organizational performance at "Barclays bank". In fact, it is quite essential to involve both the line managers and employees in the primary research process in order to get a better understanding on the issue. Hence, the different methods which would be used in the research are as follows:

\subsubsection{Questionnaire}

The first approach is to construct an engagement analysis questionnaire, which would be mixture of some open and close ended questions and these will be selected after a careful consideration of the research question. It should be kept in mind that all the questions have to be clear, valid and unambiguous in association with the phenomena, which is understudy and the questionnaire would then be handed over to the group of respondents at the bank in order to get valid and useful information about the issue, which is under debate. In addition, the author would also send an email request to the target group of line managers and employees so that they could be able to respond to the questionnaire conveniently. It is also ensured that 
the information receive would be kept confidential. This method also proposes that not everyone respond to the questionnaire because of the possibility of extraction of important and confidential data. Nevertheless, questionnaire would be a reliable method to come up with detailed insights of the argument. "The aim of this method is to find out what the respondents think, do or feel because it would help the author to address the research question comprehensively." (Collis \& Hussey, 2009). However, it is quite apparent that questionnaires always raise the issue of confidentiality but it has to be ensured to the target audience that the data would be treated confidential.

\subsubsection{Interviews}

The second approach in this research is semi structured interviews as stated by (Saunders \& Thornhill, 2008) that semi structured interviews offer the researcher the "opportunity to probe answers, where you want your interviewees to explain, or build on, their responses." In other words, semi structured interviews would play a pivotal role in seeking interpretivist paradigm of research in which your significant concerns is to understand the implication of the research that respondents are assigned to a variety of different practices and propositions (Saunders \& Thornhill, 2008). In addition, semi structured interviews would also provide a researcher in depth and comprehensive information on the question, similarly, it also leads the argument in to the areas that a researcher have not considered before, which is very crucial in terms of understanding the research question and also support the author in concentrating on the research objectives.

Consequently, it could be suggested that semi structured interviews could work as a stepping stone in order to capitalize on rich and greater understanding of the research question (Saunders \& Thornhill, 2008).

\subsection{Data Analysis}

This research of employee engagement would pursue the combined inductive and deductive approach as mentioned before that most of the researchers, who took up a mix of inductive and deductive approaches, came up with better results (Hyde,2000) so this piece of research would also be undertaken with a mixed approach.

This research is significantly based on the inductive approach that would be foremost in order to come up with the relevant data acquisition during this piece of research, which ensures valid interpretation of data analysis. However, deductive approach is also going to be used in this [piece of research, which allows structured results in order to meet the research objectives (Yin, 1994). On the contrary, deductive approach has been criticized as it lacks the in-depth analysis integrated with qualitative research.

The data analysis will be a mix of qualitative and quantitative approaches. Since, many social scientists and researchers are now agreed to view that both the qualitative and quantitative methods can be used for a valid research (smith et al, 1991). In fact, (Hyde, 200) also proposed that many researchers who took up a mix of qualitative and quantitative approaches is a balanced proposition of any type of research. Hence, this research of employee engagement entails detailed and comprehensive study of the data in order to establish 
integration or association between the data obtained from different sources. Ultimately, the first stage of analysis would include the data collection from questionnaires, which will be given to the employees of Barclays bank in order to identify engagement factors with in an organization. Eventually, various conclusions would be illustrated after this exercise with the help of which number of results could be drawn out. Likewise, the same exercise would then be undertaken in terms of semi structured interview questions, which would be posed to line managers of a company and with the help of which relevant information could be acquired in order to recognize areas of similarity or difference with the literature review.

The qualitative and quantitative data would then be analysed to identify what is happening within a firm and what could be done to improve engagement processes within the bank. Moreover, the information collected from data analysis should be associated with the literature review, so it is essential to emphasize the significant statements from the data gathered in order to discuss the findings.

\subsection{Research Limitations}

As it is illustrated before, that the focal point of this research is more on interpretive paradigm. However, it is suggested that the collection of some quantitative data can improve the validity of the research.

In addition, the questionnaire and the interview sessions would prove to be beneficial in terms of getting authentic data and this would further substantiate the research argument and its subsequent discussion and conclusion. Most specifically, verbal communication in terms of semi structured interviews would also reinforce to capitalize on driving forces or theories behind the research argument. However, the main constraints of this research is that the respondents or participants in the bank would be vulnerable, when they were asked open ended questions about disengagement processes that inhibit organizational performance. In order to alleviate this danger, the researcher must inform the respondents at every step in the process with a clear explanation of how the data would be kept confidential and this ensures that the research will be carried out ethically. However, nevertheless, it is quite difficult to verify that the data acquired is valid and authentic, as individuals within an organization might be unwilling to share the information.

\section{Research Findings and Analysis}

This section illustrates some significant findings obtained from the questionnaires and interview analysis from line managers and employees. In fact, all the questions in the questionnaire and the management interviews provided in-depth insight of the research. However, the researcher also faced a bit delay in getting the questionnaire completed. Out of 30 questionnaires, 18 came back with the response rate.

Moreover, the findings would examine the result in order to determine its consistency with the literature review and it would also ensure to how, and to what extent the data collected for this research supports the results. The findings would consist of two sub headings: questionnaire analysis and manager's interview analysis in order to present a simple layout. 


\subsection{Questionnaire Analysis}

The questionnaire consists of several questions about employee engagement. The author intends to discover the factors or propositions, which make the individuals to demonstrate vigour, pride, energy, and resilience in their jobs. Consequently, in this section the author identified 6 useful findings regarding engagement issues between line managers and employees.

4.1.1 Do you think that line manager makes the job interesting for you?

\section{A graph to show that how many respondents think that line managers make the job interesting for them. \\ $\square$ Yes $\square$ No}

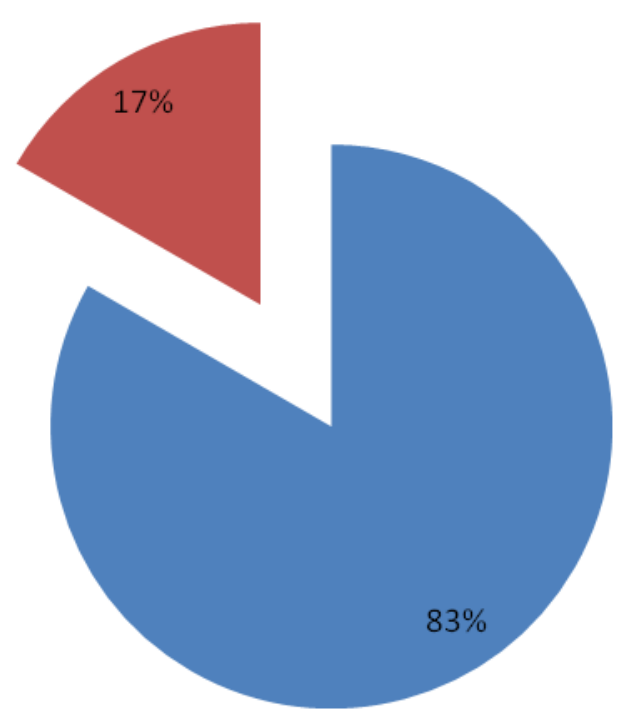

In response to this question in the questionnaire, (Appendix C) Respondents, who answered in negative, believed that they like to feel that there is someone to whom they can turn for advice or help, if they need it. Interestingly, some of the respondents believed that there is a communication gap between line managers and employees, due to which the individuals are not involved and can't bring about vigour, dedication, and pride in their work roles. If we compare this finding with the research of (Piersol, 2007) that communication and interaction between line managers and employees in terms of supportiveness, goal setting, and job design are the key drivers of engagement, which can improve organizational performance in the long run. Consequently, this indicates that line managers should cautiously think to have clear and honest communication, which is a significant management tool for employee engagement within an organization. In addition, one of the employees in a company commented that line manager's do not always promotes thoughtful communication strategies in terms of making them feel that they are listened to. Some respondents also observed that 
relationships between line managers and employees in terms of trust and friendliness is not embedded in an organization and due to which employees do not feel any interest in their jobs.

4.1.2 I am given freedom from my manager to decide how to do my job.

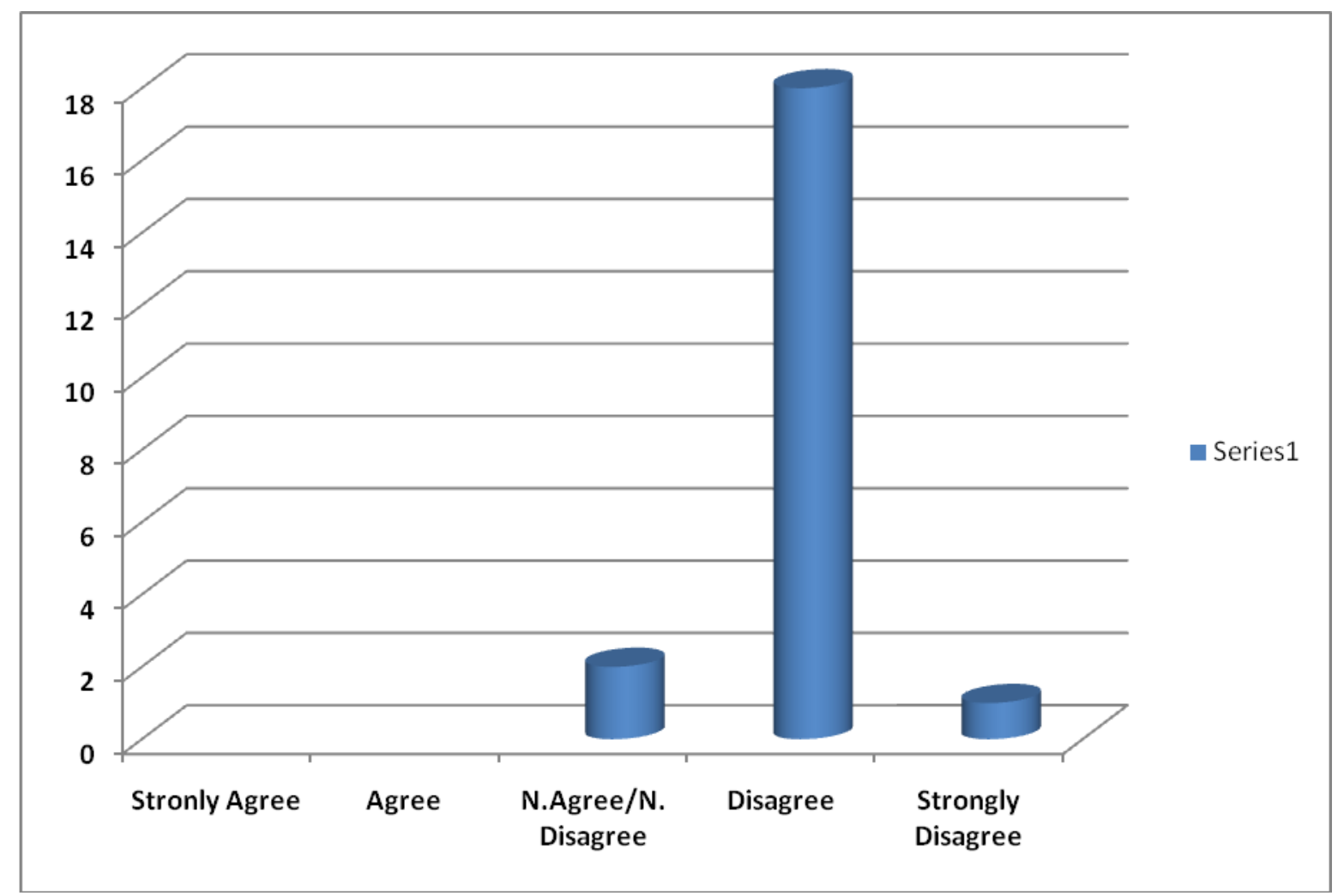

In response to the second question, (Appendix C) an overwhelming majority of $91 \%$ say that they are not given any freedom to decide on what and how to do the jobs. In other words, they are not authorised to make any decision unless ask from their line managers. Conversely, $9 \%$ of the respondents did not say anything, whether they agree or disagree with the statement. In the explanation of their views, most of the individuals said that they do not know the goals of the company and do not have a feeling of ownership and responsibility. They further stated that they do not have a sense of control that how things are done within an organization and this information exhibits that empowerment plays a significant role in making the employees to be truly engaged within their work roles and this could also be coupled with (Albert \& Hayes, 2003) research that "individuals need to be empowered, or there will be a failure". This means that line managers in Barclays bank need to select right people and give them authority to attain their optimum, so that the employees and organization could succeed simultaneously. Consequently, line managers must recognise that empowerment is the term, which is closely integrated with engagement. It also reflects that if line managers want their employees to demonstrate vigour, energy, and dedication within their jobs, they need to be empowered. 
4.1.3 I like working for my line manager

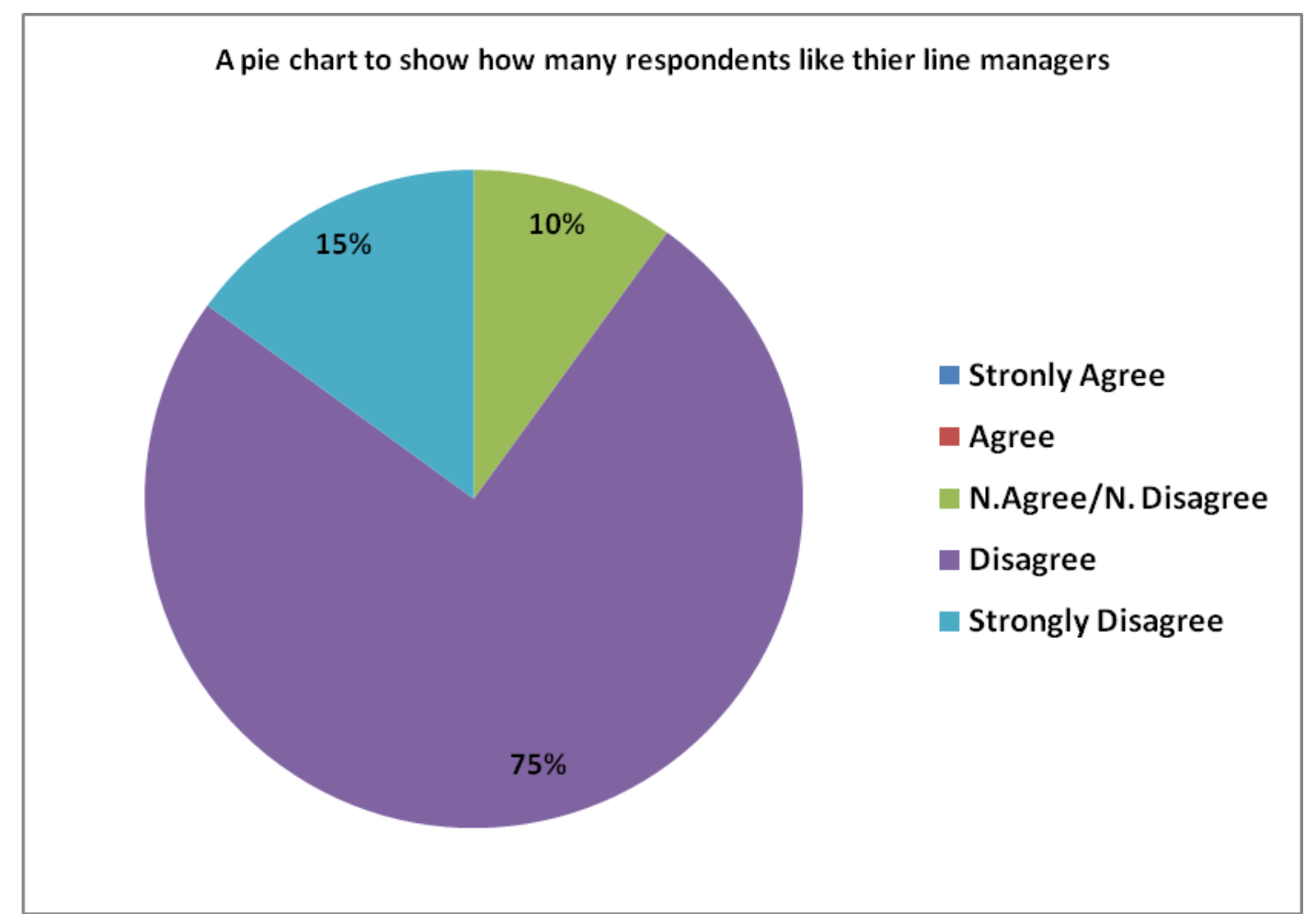

In the explanation of their views about this question (Appendix C) most of the employees think that they do not like their line managers. It is further explained by the respondents that they are not supportive enough in terms of work related problems and there is less encouragement to develop new skills within the job roles. It is also exhibited by employees that they do not encourage us in important decisions. Likewise, good work is not appreciated and praised and the treatment is not fair enough. Taken as a whole, interpersonal interactions and relationships are conspicuously absent between line managers and subordinates stated by most of the employees. In addition, if we compare this information with (Gilson \& Harter, 2004) research that supervisors or line managers should apparently focus on supportiveness and interpersonal interactions, which are quite significant ingredients in order to accomplish engagement levels within an organization. Most importantly, social support by line managers is an important factor that fosters interconnection or relatedness between employees and line managers, which enhances employee engagement at work (Gilson \& Harter, 2004). It also proposed by (Locke \& Taylor, 1990) when managers treat their employees with dignity, respect, and value for their contribution and if there is substantial interpersonal relationships with each other, employees would likely to come up with meaningfulness and engagement in their jobs. 


\section{Macrothink \\ International Journal of Human Resource Studies \\ ISSN 2162-3058 2016, Vol. 6, No. 4}

4.1.4 My contribution is recognised by my line manager

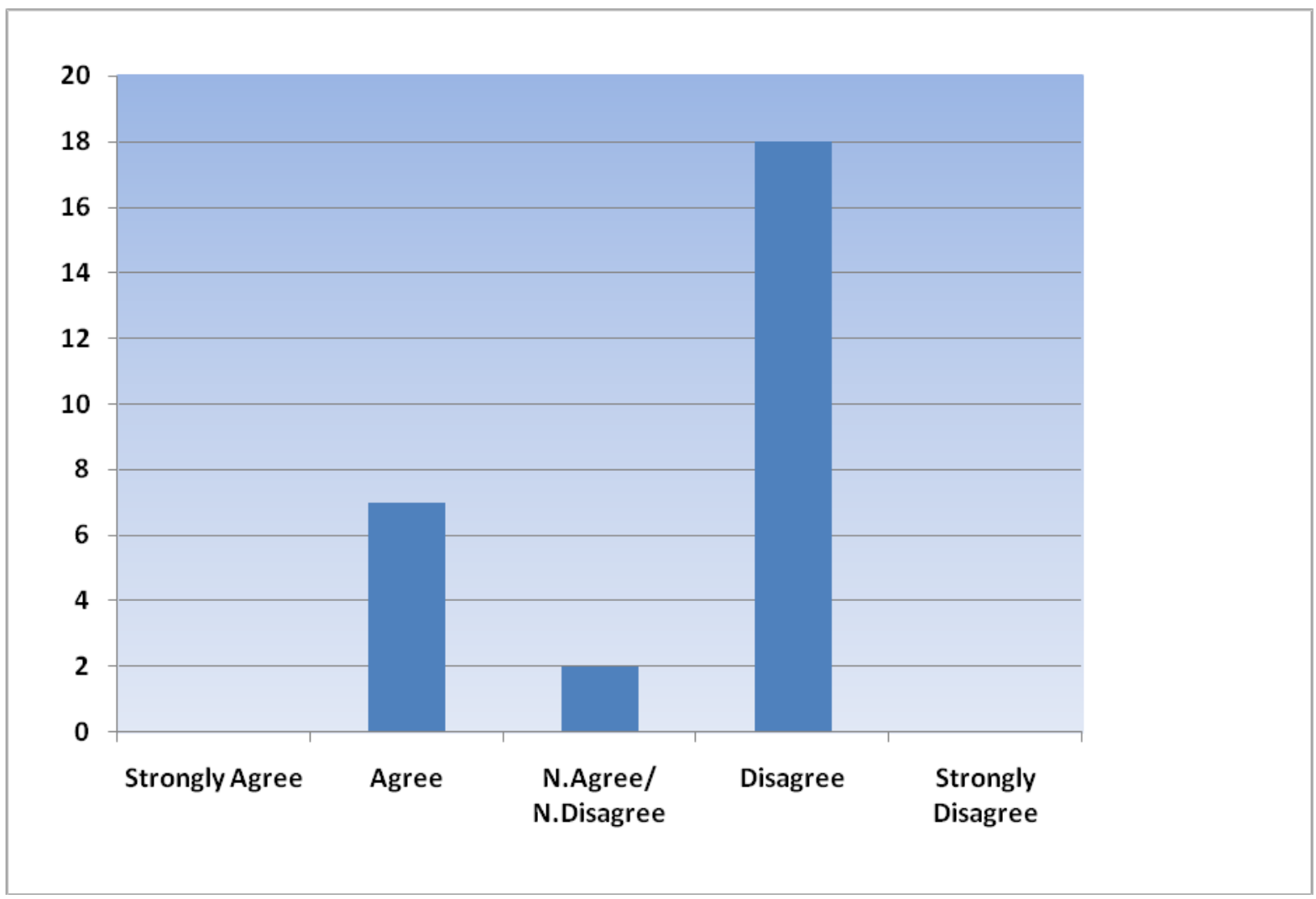

In response to this question, (Appendix C) respondents explained that their contribution is not recognized by managers. In addition, it is further argued that employees' needs and concerns are not being listened to and employees' opinions are not voiced within a firm. Seen in this light, it is argued by (Ulrich, 1996, p.29) that managers must ensure the needs of employees. There by, employee contribution goes up in order to increase financial performance of the company. When employees are engaged and committed in their work roles, this would be reflected in a company's financial profits. He further propounded that managers should listen to employee contribution and find the ways to provide the resources. Managers should come with the ways that determines the means for employees to voice their concerns and feel ownership in the business, which could ultimately enhance engagement levels over the long haul. 


\section{Macrothink}

4.1.5 I have no problem in achieving a balance between my work and private life

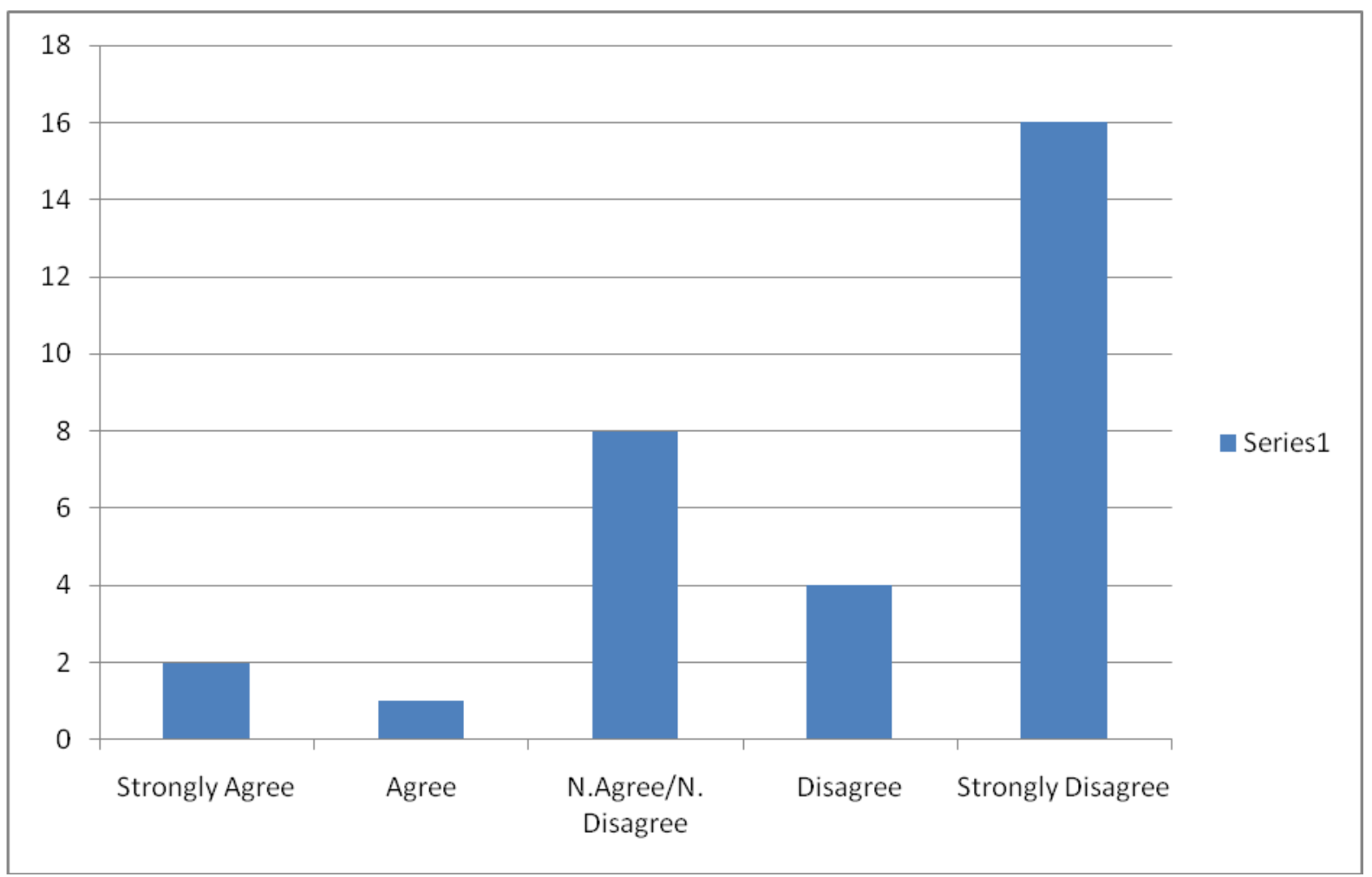

In response to this question in the questionnaire (Appendix C) Most of the employees in a company said that there is not any fit between employees work and personal life. Long working hours every other day affecting the employees' performance and this is also quite detrimental to employee health and well being. Interestingly, one of the employees in Barclays bank said that my line manager's attitude to work life balance is poor. He further explained that sometimes the bank close at 22:00 and open on Sunday's as well. If we compare these findings with the (Richman, et al, 2006) research that ability to manage the demands of work and personal life are strongly related to high levels of work engagement. In addition, (CIPD, 2006) also proposed that managers who make their employees flexible in terms of their work and private life, invariably foster a more positive work environment, where employees can flourish. Furthermore, it is quite surprising that over $80 \%$ of the respondents raised the need to focus on work life balance or flexible working practices. Likewise, one of the female individuals within the bank also suggested that as in today's corporate world women are increasingly striving to manage a career and family life, so it is crucial for managers to fit a balance around individuals' family and other commitments. 
4.1.6 I get on well with my work colleagues

A pie chart shows that how many respondents get on well with their colleagues.

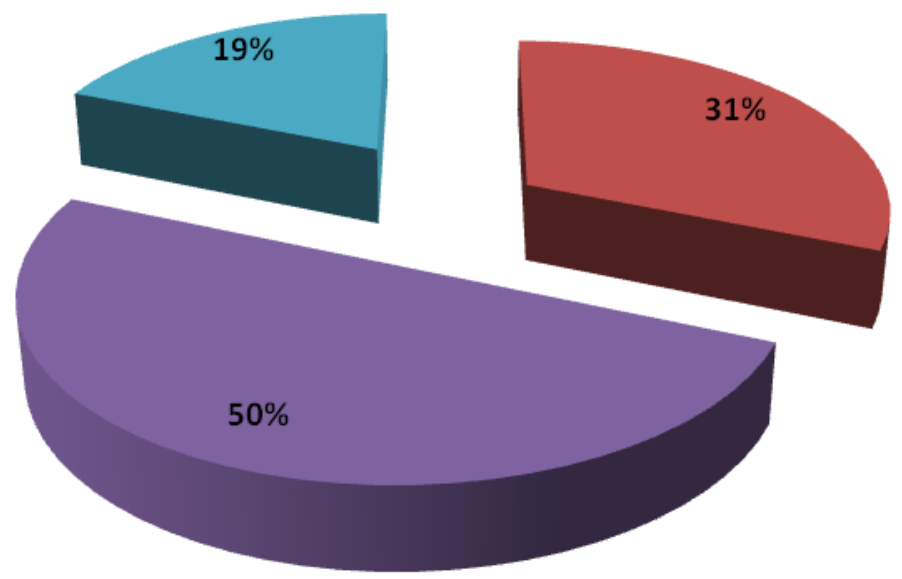

$\square$ Strongly Agree $\square$ Agree $\square$ N. Agree/N.Disagree $\square$ Disagree $\square$ Strongly Disagree

In response to this question in the questionnaire (Appendix C) majority of the respondents stated that there is a lack of cooperation and coordination between colleagues and co-workers. In other words, the interaction with the co-workers is not rewarding and employees' inputs are not valued by other colleagues. Interestingly, one of the respondents explicated that there is not a sense of real connection or mutuality between colleagues within a company; therefore they do not really feel worthwhile within their job roles. However, few individuals mentioned that they sometimes feel 'kinship' with their colleagues. If we evaluate these findings in association with (Macey, et al, 2009, p.125) literature that social support from managers gives employees to come up with better social relationships among colleagues within an organization. It is further suggested that there should be an element of trust so that they could homogeneously and mutually create a sense of belonging within a firm, which would ultimately foster employee engagement.

\subsection{Management Interview Analysis}

This section covers with the findings acquired from the semi structured interviews (Appendix D) carried out with four line managers. The summary is being discussed here.

In relation to whether the line managers in Barclays bank think engagement is significant or not, all of the managers interviewed, explicated that the bank took employee engagement processes and procedures very seriously. According to them, engagement is the only way to enhance productivity of the employees. They further proposed that it is the manager who needs to create an environment where employees feel vigorous, passionate, and energetic about their work and express the behaviours that firm needs to cultivate better financial outcomes, not only for the bank, but also for employees as individuals. They also agreed with 
the fact that

"Employee engagement is the only phenomena in today's corporate world, which could help to harness employees' efforts towards organizational performance."

On the contrary, one manager said,

"Engagement in Barclays bank has been conspicuously absent and this is the term, which is all about relationships that should be reciprocated from both sides i.e. line managers and employees."

A parallel can be drawn from this finding and (Piersol, 2007) research that "employee engagement is a bit of misnomer and engagement in an organization is not a unilateral concept but a symbiotic relationship within the whole enterprise, and management holds the primary responsibility for it. It is the ballet of empowerment and shared ownership: they go together, and you cannot have one without the other".

One manager realistically argued,

"Employee engagement is the responsibility of line managers. They should select the right individuals and develop them; create an open communication system. Employee empowerment is significant in order to provide the agility and competitive advantage to succeed".

Another manager answered (Appendix D) about the factors which inhibit engagement at the bank says that,

"There is a lack of social support and mutuality between line managers and employees due to which the bank is confronting disengagement issues and this affecting overall organizational performance. He further proposed that in order to foster a significant change in the attitudes of employees, line managers have to come up with cooperation and caring attitudes, which are pivotal in terms of augmenting engagement and organizational performance. Most specifically, the substance of connectedness and mutuality would definitely bring about vigour and energy in employees within their work roles. He further suggested that when employees have more autonomy and control and participate in decision making their engagement level rise".

Similarly, if we compare this significant finding with (Ludeman, 1990) empirical research he postulated that "a few forward looking managers do use this approach to lead people through empowerment. They recognize that everyone in a company wants to be capable and powerful. They empower their employees to make significant contributions at work to maximize their full potential, offering challenges at each level of responsibility, and managing employees with flexible organization and caring systems".

Not surprisingly, one of the other managers also mentioned that,

"There is a lack of communication between employees and line managers and as a result of that employees are not interconnected with each other and this also reduces engagement levels within the bank. It is further stated that employers should also be conscious before 
selecting individuals for the job. To put it in other way, managers should focus on individual characteristics and personality attributes when hiring. These findings could also be endorsed by (Wildermuth \& Pauken, 2008) that personality traits and attributes could matter individuals. In fact, psychometric tests would play a prominent role in order to identify certain specific traits of individuals for instance, extraversion, hardiness, and resilience”.

In addition, when line managers asked about whether they think empowerment, communication, and flexible work/life balance (Appendix D) are important drivers for employee engagement, the general opinions were in affirmative. "The management feel that communication is pivotal in terms of engaging employees. No employee could be engaged automatically, unless it is developed. Interestingly, one of the managers stated that employees need to be feel that they are valued partners so that they could their jobs with vigour and energy. In addition, he further illustrated that flexible work schedule is also significant and this is one of the crucial factors, which is alleviating the engagement processes within the bank and also affecting financial performance of the company". This is quite a thought provoking issue, which should be addressed within a bank. Most specifically, line managers need to ascertain the demands of work and personal life of employees that are strongly integrated to higher levels of employee engagement. This crucial finding could be drawn parallel with (Richman, 2006) research that flexible work arrangements are linked with better mental health and resilience, greater productivity and effectiveness.

However, in response to the question about flexible work (Appendix D) one manager explained briefly that flexible work/life balance could only be facilitated, when there is an element of social support and relatedness between line managers and employees and this could only be ensured when line managers express sensitivity and concerns for employee's needs and feelings.

In response to the question about rewards and recognition, (Appendix D) majority of the managers said,

"Rewards, recognition, and praise are very significant ingredients in terms of enhancing engagement levels within the bank. Employees thrive on praise and managers need to know that since they will generally treat others as they treat themselves. Most importantly, they should begin to recognise their own good qualities and successes". This postulation is also explained by (Ludeman, 1990) that "when line managers agree that they need to praise and recognise their employees but then fail to put their good intentions in to action, they are stumbling because they have not uncovered the attitudes and values that lie under their behaviour for instance, once managers have silenced their own personal critic and are personally convinced that they are praise worthy and capable, they are ready to believe that others, too, are worthy". Most specifically, they empower themselves and those who work within a bank. They do their best to develop employees' skills and talents (Ludeman, 1990).

Another manager said that financial rewards are also important in terms of salary, benefits and other perks. However, it could be argued that rewards are classified in two types' intrinsic rewards and extrinsic rewards and it is the line managers in Barclays bank, who have to discover which reward an employee is looking for. As (Lincoln \& kalleberg, 1990) have 
proposed that "rewards offered by an organization may have a powerful effect on employees' attitudes towards their job and company for which they work". In this perspective, it is significant to differentiate between intrinsic and extrinsic rewards. Intrinsic rewards are those that exist within a job, such as recognition, variety, challenge and autonomy (Caldwell et al, 1990). Extrinsic rewards, on the other hand, constitute elements such as pay and fringe benefits, promotion and advancement opportunities within an organization. In this perspective, the line managers need to identify within the employees that, which one of those would contribute to foster engagement in a bank.

The analysis seems to show consistency between the different methods of research both in the literature review and in the primary data collection. The results show the need for line managers in Barclays bank to focus on promoting communication and also to ensure the element of relationships between line managers and employees. Areas of improvement include communication, empowerment, social support and relationships, rewards and recognition, selection strategies, and mutuality between line managers and employees.

\subsection{Discussion}

The purpose of this study is to discover the engagement related issues within the Barclays bank and to explore the proposed measures to resolve the problem.

Literature would agree that line managers interventions in harnessing the efforts towards employee engagement practices have a crucial impact to improve organizational performance. In fact, the secondary research in the literature review would also lead us to believe that line manager implication play a pivotal role in the restoration of workers disengagement levels in to meaning. Seen in this light, (McBain, 2007) explicated that managers probably have the greatest impact on engagement as they create an atmosphere in which the employees feel meaning and psychologically safe within their job roles.

In addition, research has also suggested that the key skill that line managers need in order to foster engagement and organizational performance is communication. Significantly, these findings have been identified in the literature review as a major cause of inhibiting engagement levels within the company. It is therefore, important for line managers to ensure clear, honest, and consistent communication to get the employees' personal fulfilment and meaningfulness within their work roles. However, lack of communication can lead towards dissatisfaction, disengagement, and distrust among employees.

The research has also identified empowerment as a crucial factor to enhance employee engagement. This area has been informed by a through review of both the literature and research findings. In fact, most of the employees feel that they do not have autonomy within their job roles and not authorised to make any decisions unless ask from their line managers. According to (spreitzer, et al. 1997) "Indeed, much of the recent literature on empowerment and employee involvement focuses on providing meaningfulness and psychologically safe work to employees" to facilitate employee engagement. Empowerment can also make the employees feel passionate and energetic in the jobs. However, (Piersol, 2007) stated that "employee empowerment is the term that could be used over employee engagement" because 
it correctly reflects that line managers has overwhelming responsibility in promoting engagement. Consequently, this is quite significant area in the findings, which must be improved by line managers within an organization.

Furthermore, in the area of social support and relationships, majority of the respondents felt that social interaction and relationships have conspicuously been absent between line managers and employees and good work is not encouraged and appreciated. In fact, the literature explained an association between the element of relationships, social support, and employee engagement and strongly advocates the need for this. Seen in this light, (Gilson \& Harter, 2004) propounded that the relationship with the immediate manager can have a dramatic impact on an individual's perception of psychological safety, availability, and meaningfulness in a work environment, which could subsequently foster engagement and organizational performance. This significant finding also consistent with literature review seems to be root cause of disengagement levels and must be restructured by line managers within a bank. However, this element of social support and relationships should be reciprocal from both the sides i.e. employees and line managers.

With regards to management interview analysis, almost all the managers emphasized the need of co-workers relations, which is apparently disappeared within a bank. They believed that there is a lack of cooperation and coordination among employees and they are not mutually connected with each other. If we compare this significant finding with (Locke \& Taylor, 1990) research, which is consistent with the literature review that individuals who have interpersonal interactions and coordination between each other, they experience greater meaning and availability in their work. Literature in organizational behaviour also identified this important element of mutuality and connectedness among colleagues. According to (Gilson \& Harter, 2004) that individuals also obtain a sense of pride and meaningfulness from each other's interactions and the social identities they receive from group members. This ultimately, advances a sense of belonging, mutuality, and relatedness, a deep sense of social identity would also emerge (Gilson \& Harter, 2004). Eventually, this significant need should also be taken in to consideration while implementing the action plan to enhance engagement processes within the bank.

Furthermore, line managers' interventions in the flexible work/life balance were described in the interview as 'ad hoc' rather than strategic. Literature suggests that workplace flexibility is associated to positive outcomes for the employees and for the organization as well. Line managers' ability to manage the demands of work and personal life are integrated with enhanced employee engagement (Richman, 2006). These significant findings were confirmed that flexible work arrangements are positively aligned with better mental health and resilience at work.

The research findings also emphasized the need of being challenged, which should be brought in to light by line managers. Employees like to feel challenged there by, believing that they have the necessary tools and skills to respond successfully. In addition, another area as recognized by the findings is an element of trust and friendliness among employees and line managers. Feeling trusted makes one feel a useful part of the team and when employees 
feel trusted, they are more likely to feel a useful part of the team.

Taken as a whole, the findings corroborated various areas to enhance engagement levels in order to improve organizational performance. Consequently, it could be proposed that when line managers share control, they demonstrate significant trust in and respect for their employees in the form of praise and contribution (Rosen \& Jerdee, 1977). Employees' values being involved in the decision making process and they are given autonomy within their job roles. In fact, the emphasis in communication is on sharing and exchanging ideas and most specifically, the element of mutuality and connectedness towards organizational goals. Ultimately, it can be concluded that all these factors, if implemented cautiously by line managers would likely to promote employee engagement in order to come up with greater organizational performance.

\section{Conclusion}

This section corroborates earlier findings which have been discussed before in questionnaire analysis part from employees and the management interview analysis. Taken as a whole, all the findings outlined key factors that line managers in Barclays bank should adopt to reduce disengagement levels in order to improve organizational performance within a bank. As a matter of fact, various factors have been found, if overcome appropriately, and then engagement processes would be ameliorated. It is discovered in the research that line managers had a strategic role in the implementation of employee engagement levels and exercise their discretion to alleviate the issues, which inhibit employee engagement and organizational performance as well.

The report has identified various areas that could be improved by line managers in Barclays bank. The research highlighted that communication is one of the significant components to enhance engagement levels as this is one of the issues, which most employees are confronting. Seen in this light, it is stated by (Wallace \& Trinka, 2009) that conversation or communication with employees play a vital role and leave an everlasting affect on employee performance. When employees feel good about the impact of their efforts, they engage more thoroughly in those efforts that bring about high levels of employee engagement, point out the valuable contribution of each employee's work to the overall organizational picture and demonstrate regular appreciation for that work contribution, would definitely affect organizational performance. In addition, empowerment is also one of the issues which needs to be addressed. As (piersol, 2007) explicated that "perhaps employee empowerment is the term that should be used over employee engagement" because it correctly reflects that management has the overwhelming responsibility in promoting engagement that could make happen vigour, energy, and resilience in their jobs. Seen in this light, it is significantly crucial for line managers to challenge and empower employees in order to improve organizational performance. Research tends to concentrate on this issue and action steps needs to be taken to address this.

Many of the engagement issues must be linked in to what employees want from their line managers. Social support, relationships, rewards and recognition, mutuality, empowerment, and work/life balance mentioned prominently in the results. Research also highlighted line 
managers' interventions in HR policies would be a significant factor in the implementation of engagement processes within a bank. In particular, employee's autonomy or work empowerment would work as a stepping stone to promote engagement and organizational performance. Most individuals, specifically talented individuals likely to be able to get on a roll as far as work are concerned. A degree of real autonomy, where someone can really get in to his job, is likely to be ensured within a bank.

The report also tended to concentrate on the implication of social support and relationships between employees and line managers within a bank. Employees like to feel that there is someone to whom they can turn for advice, if they need it (Woodruffe, 2006). Furthermore, flexible work life balance should also be ensured by line managers within a bank and employees must know they are going to work hard, but managers who show sensitivity to work life balance is likely to outscore one who does not (Woodruffe, 2006).

The report also emphasized that feeling of being challenged, which should be brought to light by line managers within the employees. In fact, employees like to feel challenged, thereby, believing that they have the necessary tools and skills to respond successfully. Another area which should be embedded within an organization is the substance of trust and friendliness between line managers and employees. In particular, feeling trusted makes one feel a useful part of the team. Individuals are social animals and when employee feel trusted, they are more likely to feel a useful and important part of an organization and more likely to foster engagement within a bank. Consequently, Line managers need to make sure that this feeling should be addressed in order to improve engagement and organizational performance.

In addition, report has also tended to concentrate on the accountability issue, which is one of the significant components to discover engagement. Employees are more engaged when their managers effectively hold them and their teams accountable for results. An individual employee may be doing great work; however, other employees might be lagging behind. If a manager does not do something to rectify the situation, it disengages team members. This need should be ensured to alleviate disengagement in order to improve organizational performance.

The report also indicated the need for rewards and benefits, in fact, high salaries or wages would definitely demonstrate vigour, energy and pride in employees and this would ultimately foster engagement and organizational performance, so this need should also be cascaded within a bank.

The research also highlighted the necessity of employee selection. In this perspective, managers should be conscious to identify individual personality characteristics and attributes when hiring. A parallel can be drawn with (Gubman, 2004, p.42) argued that if engagement is a "heightened personal connection to the organization" research should focus on the person rather than on other factors. Its being revealing that managers should significantly recognise individual attributes and traits in order to enhance employee engagement within a bank.

Moreover, line managers interventions has also been identified in the report that "devolution of personnel practices to the line, on the one hand, means that line managers should become 
more involved in HRM at the operational level and, on the other hand, that HR staff are freed up to take on board a greater strategic role." (Sisson \& Storey, 2000).

This report concentrated on various areas which line managers should espoused to promote employee engagement in order to induce organizational performance. However, employee engagement is a complex concept with many issues influencing engagement levels. Consequently, there are many corridors to discover engagement, with no one kit that fits all organizations. Ultimately, the key to effective engagement can result when employee has job autonomy, social support, rewards and recognition, relationships and mutuality and most specifically communication. Seen in this light, (CIPD, 2009) proposed that "managers should consider allowing individuals the opportunity to feed their views and opinions upwards is the single most important driver of engagement. Keeping employees informed about what is going on in the organization is critical. Employees need to see that managers are committed to the organisation in order to feel engaged and having fair and friendly management processes for dealing with problems is significant in driving up the levels of performance".

\section{Recommendations}

This section would suggest an action plan for line managers in Barclays bank to address engagement issues.

- $\quad$ Line managers in Barclays bank needs to crop up with clear, consistent, and honest communication, which is pivotal in terms of inducing employee engagement within the bank. In fact, line managers should promote thoughtful communication strategies that encourage engagement in order to keep their workforce vigorous, energized, focused, and productive. Such strategies are crucial to long term organizational performance. However, lack of communication or poorly communicated information can lead to distrust, low morals, and dissatisfaction among employees within their job roles. In particular, line managers need to ensure and maintain an open dialogue among employees and listen to them carefully what employees want and need. Regular communication with employees is essential, so managers should proactively communicate with employees in order to facilitate employee engagement and trust, which in turn can impact on productivity levels in the bank. Consequently, it has concluded by (CIPD, 2009) that "line managers should allow the individuals the opportunity to feed their views and opinions upwards, which is the single most important driver of employee engagement" and ultimately intensify organisational performance. Seen in this light, line managers should know how to contextualize engagement with communication that helps to make employees involved and engaged within their jobs, so communication strategy should be reviewed appropriately by line managers within the bank in order to identify exactly what undermines engagement processes.

- Line managers in the bank need to address employee selection processes, which is another management responsibility in this equation. Since, engagement levels are influenced by employees' personal characteristics and attributes, so line managers need to ensure that they put a premium on personality characteristics and this could be 
measured with the help of psychometric tests. In addition, line managers within the bank should also endeavour to execute empowerment. In this context, line managers need to ensure that employees are involved in decision making and they have autonomy and freedom to voice their ideas, to which managers listen to and feeling enabled to perform well in orders to reinforce organizational performance. As (CIPD, 2009) illustrated that "flow and engagement can result when an employee has job autonomy, support, feedback, task variety, and responsibility".

- Satisfaction with pay and rewards is also associated with engagement, so a review of salaries and rewards need to be carried out to substantiate that employees are being paid and rewarded fairly. On the contrary, non financial rewards such as recognition, praise and feeling of being trusted are significant to foster engagement. It is also important for line managers to consistently and frequently recognise their employees for their good work and this could be a simple thank you or congrats. Consequently, recognition has a huge impact on engagement and line managers need to ensure that this should be embedded as a benchmark to increase engagement and organizational performance within the bank.

- One strategy that could add value to the organization is flexible work/life balance. By ameliorating the work/life balance of employees the research would suggest that engagement will improve. In this perspective, line managers need to establish policies and practices such as allowing employees a degree of choice in terms of how they manage their work balance. In addition, the content of the job is also meaningful to the employee, so line managers need to ensure that the jobs are carefully structured and the working environment there by, creating a meaningful work for everyone, leads to foster engagement and organisational performance.

- Line managers need to create an environment where employees feel more passionate, pride, and vigour about their work and exhibit the behaviours that organizations need to drive better results, not only for the organization, but also for employees as individuals. In order to achieve this, line managers should come up with better social support and relationships among co workers. In particular, they need to ensure that a supportive work environment should be displayed to accomplish employees' needs and provide positive feedback and encourage them to voice their concerns, develop new skills and solve their problems (Deci \& Ryan, 1987). Such kind of supportive actions make the employees feel psychologically safe and lead to feelings of availability and meaningfulness at job, which would ultimately, increase organizational performance.

- Line managers in Barclays bank need to create more opportunities to enhance interpersonal interactions among co-workers, so that the employees could promote greater meaning in their work. Seen in this light, literature in organizational behaviour identifies that individuals possess the needs of mutuality and relatedness (Locke \& Taylor, 1990). Managers need to make sure that employees should be treated with dignity, respect, and value for their contributions and these gestures would likely to 
obtain a sense of meaningfulness, psychological safety, and improving morale from their interactions. Consequently, it could be concluded that co-worker interactions and relationships foster a sense of belonging and engagement within an organization, so in this perspective, an action plan must be created to implement these concerns.

In short, it could be concluded that line managers in Barclays bank need to combine all those strategies in order to boost engagement levels and must begin to focus on delivering employees needs and values. Most significantly, when measuring engagement, line managers could look at the factors such as employees' pride in the organization, belief in its products and services, belief that managers enable them to perform well, promotes social support and relationships, a willingness to make them demonstrate vigour, pride, and energy in their work roles and consequently, developing a work environment in which employees are valued, recognized, and rewarded (IES, 2009).

\section{Research Limitations}

In relation to the limitations of this report, the research is based on only one branch of the bank and does not cover the rest of the branches all over the city and beyond. Moreover, while conducting the primary research, the author did not take interviews of everyone in the bank. However, undertaking a research to include everyone is quite irrational in terms of cost and time restrictions. In addition, the author undertook semi structured interviews from line managers to obtain the relevant data. However, if the interviews had been conducted in unstructured or detailed form, the findings would have been explored more. Likewise, the author also confronted a bit difficulty in terms of time limitations because of the busy schedule of line managers in the bank, which in turn significantly reduced the time available to execute the primary research, and the subsequent analysis of the data obtained.

Moreover, this study has also been deteriorated in terms of obtaining information from the employees, who were quite new to the company and seemed to be a bit nervous or afraid in giving the right information and in this regard, I assume that the data came out from new comers might be rhetoric rather than reality and this significantly lessen the validity of the result.

Since, employee engagement is quite contemporary or conventional topic, the author found some problems in getting the relevant journal articles. In fact, this research is somehow integrated with psychological aspects of human behaviour, so the journal articles I found useful were in the psychology section at NORA not in business and management section.

The major limitation, for this piece of research would also be that the researcher, not being part of the management, could only offer recommendations and suggestions in order to facilitate a change rather than implying the same.

\section{Implications for Future Research}

There are several imperfections and deficiencies, which are raised with this piece of research and should be ameliorated for future investigations. As a matter of fact, it would be quite useful to undertake focus group surveys with the employees and unstructured or detailed 
interviews from the line managers of the same branch to gain in-depth insights, factors, and propositions in order to promote employee engagement processes and procedures within the bank.

In addition, it would also quite supportive to emphasize the need of training and development for both the employees and line managers within the research project. In particular, the notion of training and development should also be pursued in both the questionnaire and semi structured interviews in such a way, that how training and development of managers and employees would enhance engagement and organizational performance.

With its conceptual link to psychology, it is also important to seek secondary research in organizational psychology in order to get a better understanding of the work engagement factors and paradigms. Consequently, it could be proposed that future research on psychological processes at work would probably result in more sophisticated models that could contribute to more comprehensive understanding of engagement processes.

\section{References}

Armstrong, M (2008) Strategic human resource management. $4^{\text {th }}$ edn. London: Kogan Page.

Aseletine, K. \& Alletson, K (2006) 'A new deal for the $21^{\text {st }}$ century workplace', Ivey Business Journal, 70(4), 1-9. Available at: http://search.ebscohost.com (Accessed: 10 Oct 2009).

Avery, D. \& Mckay, P (2007) 'Engaging the aging workforce: The relationship between perceived age similarity, satisfaction with co-workers, and employee engagement', Journal of Applied Psychology, 92(6), pp. 1542-1556. Available at: http://search.ebscohost.com (Accessed: 3 Oct 2009).

Baumark, R. \& Gorman, R (2006) 'Why manager are crucial to increasing engagement', Strategic HR Review, 5(2), pp.24-34. Available at: http://www.emeraldinsight.com (Accessed: 12 Oct 2009).

Bond, S. \& Wise, S (2003) 'Family leave policies and devolution to the line', Personnel Review, 32(1), pp. 58-73. Available at: http://www.emeraldinsight.com (Accessed: 15 Oct 2009).

Budhwar, P.S (2000) 'Evaluating levels of strategic integration and devolvement of human resource management in the UK', Personnel Review, 29(2), pp. 141-161. Available at: http://search.ebscohost.com (Accessed: 14 Oct 2009).

CIPD (2009) Available at: http://www.cipd.co.uk (Accessed: 12 Oct 2009).

Collis, J. \& Hussey, R (2009) Business research. Hampshire: Macmillan.

Cooper, D. \& Schindler, P (2008) Business research methods. $10^{\text {th }}$ edn. New York: McGraw Hill. 


\section{Macrothink}

International Journal of Human Resource Studies

ISSN 2162-3058

2016, Vol. 6, No. 4

Cunningham, I. \& Hyman, J (1999) 'Devolving human resource responsibilities to the line: beginning of the end or new beginning for personnel', Personnel Review, 28(1), pp. 9-27. Available at: http://search.ebscohost.com (Accessed: 13 Oct 2009).

Deci, E.L. \& Ryan, R,M (1985) Intrinsic motivation and self determination in human behaviour. New York: Plenum.

Fisher, C (2004) Researching and writing a dissertation: for business students. Essex: Prentice Hall.

Fleming, J. H \& Harter, J. K (2005) 'Manage your human sigma', Harvard Business Review, 83(7/8), pp. 106-114. Available at: http://search.ebscohost.com (Accessed: 12 Oct 2009).

Gardner, D.G. \& Cummings, L (1989) 'Focus of attention at work: construct definition and empirical validation', Journal of Occupational Psychology, 62, pp. 61-77. Available at: http://www.emeraldinsight.com (Accessed: 12 Oct 2009).

Gibb, S (2003) 'Line manager involvement in learning and development: small beer or big deal', Employee relations, 25(3), pp. 281-293. Available at: http://search.ebscohost.com (Accessed: 16 Oct 2009).

Gill, J. \& Johnson, P (2002) Research methods for managers. $3^{\text {rd }}$ edn. London: Sage.

Gilson, R. \& Harter, M (2004) 'The psychological conditions of meaningfulness, safety, and availability and the engagement of human spirits at work', Journal of Occupational Psychology, 77, 11-37. Available at: http://search.ebscohost.com (Accessed: 1 Oct 2009).

Gubman, E (2004) 'From engagement to passion for work: the search for missing person', Human resource Planning, 27(3), pp.42-46. Available at: http://search.ebscohost.com (Accessed: 10 Oct 2009).

Heery, E. and Noon, M (2008) Dictionary of human resource management. Oxford: Oxford University Press.

Henson, R (1997) 'Analysis of the concept of mutuality', Journal of Nursing Scholarship, 29(1), pp. 77-81. Available at: http://search.ebscohost.com (Accessed: 3 Jan 2009).

Hyde, K.F (2000) 'Recognizing deductive processes in qualitative research', Qualitative Market Research: An International Journal, 3(2), pp. 82-89. Available at: http://www.emeraldinsight.com (Accessed: 7 Nov 2009).

Ho, V. \& Wong, S (2009) 'A tale of passion: linking job passion and cognitive engagement to employee performance', Journal of Management Studies', pp.1-22. Available at: http://www.interscience.wiley.com (Accessed: 14 Oct 2009).

Howard, P.J. \& Howard, J.M (2001) The owners manual of personality at work. Marietta: GA.

IES (2009) Available at: http://www.employment-studies.co.uk (Accessesd: 13 Oct 2009). 
Janssen, P. \& Schaufeli, W.B (1999) 'work related and individual determinants of three burnout dimensions', Work and Stress, 13(1), pp.74-86. Available at: http://search.ebscohost.com (Accessed: 12 Oct 2009).

Kahn, W (1990) 'Psychological condition of personal engagement and disengagement at work', Academy of Management Journal, 33, pp. 692-724.

Kahn, W. A (1992) 'To be fully there: psychological presence at work', Human Relations, 45, pp. 321-349. Available at: http://www.sciencedirect.com (Accessed: 16 Oct 2009).

Langelaan, S. \& Doornen, L. J (2006) 'Burnout and work engagement: do individual difference make a difference?', Personality and Individual Differences, 40, pp. 521-534. Available at: http://search.ebscohost.com (Accessed: 15 Oct 2009).

Lashinger, H. \& Wilk, P (2009) 'Empowerment, engagement and perceived effectiveness in nursing work environments: does experience matter', Journal of Nursing management, 17, pp. 636-646. Available at: http://search.ebscohost.com (Accessed: 12 Oct, 2009).

Lockwood, N (2007) 'Leveraging employee engagement for competitive advantage', HR Review, 52(3), pp. 1-11. Available at: http://search.ebscohost.com (Accessed: 19 Oct 2009).

Ludeman, K (1990) 'How do you train managers to care about their employees', Business Forum, 15(2), pp. 12-14. Available at: http://search.ebscohost.com (Accessed: 15 Oct 2009).

Luthans, F. \& Peterson, S (2001) 'Employee engagement and manager self efficacy', Journal of Management Development, 21(5), pp. 376-387. Available at: http://www.sciencedirect.com (Accessed: 15 0ct 2009).

Macbain, R (2007) 'The practice of engagement', Strategic HR Review, 6(6), pp. 16-19. Available at: http://search.ebscohost.com (Accessed: 16 Oct 2009).

Mackenna, E. and Beech, N (1995) The essence of human resource management. Essex: Pearson.

Macey, W. \& Schneider, B (2009) Employee engagement. Oxford: Blackwell.

Mankin, D.P (2003) 'Ambiguity and elusiveness: the principal characteristics of the relationship between HRM and HRD', Human Resource Management, Available at: http://www.interscience.wiley.com (Accessed: 15 Oct 2009).

Maslach, C. Schaufeli, W (2001) 'Job burnout', Annual Review of Psychology, 52(1), pp.397-422. Available at: http://search.ebscohost.com (Accessed: 10 Oct 2009).

Meyer, J. \& Allen, J (1991) 'A three component conceptualization of organizational commitment', Human Resource management Review, 1(1), pp. 61-89. Available at: http://www.emeraldinsight.com (Accessed: 17 Oct 2009).

Meyer, J. \& Allen, J (1997) Commitment in the workplace: Theory, research, and application. Canada: Sage.

Pegg, T (2009) 'Creating engagement through employee benefits', Strategic HR Review, 8(2), 
pp. 5-12. Available at: http://www.emeraldinsight.com (Accessed: 19 Oct 2009).

Piersol, B (2007) 'Employee engagement and power to the edge', Performance Improvement, 46(4), pp.30-33. Available at: http://www.interscience.wiley.com (Accessed: 25 Oct 2009).

Renwick, D (2003) 'Line manager involvement in HRM: an inside view', Employee Relations, 25(3), pp. 262-280. Available at: http://www.emeraldinsight.com (Accessed: 25 Oct 2009).

Richman, A \& Brennan, R (2008) 'The relationship of perceived flexibility, supportive work life policies, and use of formal flexible arrangements and occasional flexibility to employee engagement and expected retention', Community, Work, and Family, 11(2), pp. 183-197. Available at: http://www.emeraldinsight.com (Accessed: 20 Oct 2009).

Robison, J (2007) 'The business benefits of positive leadership', Gallup Management Journal, pp. 1-5. Available at: http://search.ebscohost.com (Accessed: 20 Oct 2009).

Rothbard, N. P (2001) 'The dynamics of engagement in work and family roles', Administrative Science Quarterly, 46, pp. 655-684. Available at: http://search.ebscohost.com (Accessed: 17 Oct 2009).

Saunders, M. \& Thornhill, A (2008) Research methods for business students. $4^{\text {th }}$ edn. Essex: Prentice Hall.

Schaufeli, W. \& Bakker, A (2004) 'Job demands, job resources, and their relationship with burnout and engagement: a multi sample study', Journal of Organizational Behaviour, 25, pp. 293-315. Available at: http://search.ebscohost.com (Accessed: 4 October 2009).

Seijts, G. H. \& Crim, D (2006) 'what engages employees the most or the ten c's of employee enagement', Ivy Business Journal, 70(4), pp. 1-5. Available at: http://www.emeraldinsight.com (Accessed: 3 Nov 2009).

Sonnentag, S (2003) 'Recovery, work engagement, and proactive behaviour: a new look at the interface between nonwork and work', Journal of Applied Psychology, 88(3), pp. 518-528. Available at: http:// www.emeraldinsight.com (Accessed: 13 Oct 2009).

Terzo, G (2005) 'Report links management to profitability', Workforce Management, pp. 19-0. Available at: http://www.sciencedirect.com (Accessed: 7 Nov 2009).

Thompson, C. A. \& Lyness, K. S (1999) 'When work-family benefits are not enough: the influence of work-family culture on benefit utilization, organizational attachment, and work family conflict', Journal of Vocational Behaviour, 54(3), pp. 392-415. Available at: http://search.ebscohost.com (Accessed: 18 Oct 2009).

Ulrich, D (1998) 'A new mandate for human resources', Harvard Business Review, 76(1), pp.124-131. Available at: http://search.ebscohost.com (Accessed: 28 July 2009).

Ulrich, D. \& Brockbank, W (2005) The HR value proposition. Boston: Harvard Business School Press. 


\section{$\triangle$ Macrothink}

International Journal of Human Resource Studies

ISSN 2162-3058

Wah, L (1999) 'Engaging employees a big challenge', Management Review, 88(9), pp. 10-0. Available at: http://search.ebscohost.com (Accessed: 2 Nov 2009).

Wallace, L \& Trinka, J (2009) 'Leadership and employee engagement', Journal of Public Management, 91(5), pp. 10-14. Available at: http://search.ebscohost.com (Accessed: 19 Oct 2009).

Watson, S. \& Maxwell, G (2006) 'Line managers'views on adopting human resource roles: the case of Hilton (UK) hotels', Employee Relations, 29(1), pp. 30-49. Available at: http://www.emeraldinsight.com (Accessed: 15 Oct 2009).

Watson, S. \& Hughes, M (2004) 'Scottish visitor attractions: managerial competence requirements', Journal of European Industrial Training, 28(1), pp.39-66. Available at: http://search.ebscohost.com (Accessed: 16 Oct 2009).

Welch, J. \& Welsh, S (2006) 'How healthy is your company', Business week, pp. 4-0. Available at: http://search.ebscohost.com (Accessed: 9 Nov 2009).

Whittaker, S. \& Marchington, M (2003) 'Devolving HR responsibility to the line: threat opportunity or partnership', Employee Relations, 25(3), pp. 245-261. Available at: http://www.emeraldinsight.com (Accessed: 12 Oct 2009).

Widermuth, C. \& Pauken, P (2008) 'A perfect match: decoding employee engagement, engaging jobs and individuals', Industrial and Commercial Training, 40(4), pp.206-210. Available at: http://search.ebscohost.com (Accessed: 10 Oct 2009).

Whitener, E., Werner, J., Brodt, S., \& Korsgaard, M (1998) 'Managers as initiators of trust: An exchange relationship frame work for understanding managerial trustworthy behaviour', Academy of Management Review, 23(3), pp. 523-530. Available at: http://search.ebscohost.com (Accessed: 13 Oct 2009).

Woodruffe, C (2006) 'The crucial importance of employee engagement', Human Resource Management Journal, 14(1), pp. 3-5. Available at: http://www.emeraldinsight.com (Accessed: 15 Oct 2009).

\section{Bibliography}

Driscoll, M. \& Randall, D (1999) 'Perceived organizational support, satisfaction with rewards, and employee job involvement and organizational commitment', Journal of Applied Psychology, 48(2), pp. 197-209. Available at: http://www. emeraldinsight.com (Accessed: 19 Oct 2009).

Domm, R (2001) 'Strategic Vision: Sustaining employee commitment', Business Strategy Review, 12(4), pp. 39-48. Available at: http://www.emeraldinsight.com (Accessed: 12 Oct 2009).

Guest, D. \& Thomas, A (1993) 'The impact of employee involvement on organizational commitment and 'them and us' attitudes', Industrial Relations Journal, 24(3), pp. 191-200. Available at: http://search.ebscohost.com (Accessed: 15 Oct 2009). 


\section{MInstitute Macrothink $_{\text {Int }}$}

International Journal of Human Resource Studies

ISSN 2162-3058

Hall, D. T. \& Richter, J (1989) 'Balancing work life and home life', Academy of Management Review, 2, pp. 212-223. Available at: http://www.emeraldinsight.com (Accessed: 12 Oct 2009).

Harter, J. \& Hayes, T (2002) 'Business unit level relationship between employee satisfaction, employee engagement, and business outcomes: a meta analysis', Journal of Applied Psychology, 87, pp. 268-279. Available at: http://www.sciencedirect.com (Accessed: 14 Oct 2009).

Kahn, W (1992) 'To be fully there: psychological presence at work', Human Relations, 45, pp.321-350.

Jones, J. \& Harter, J (2005) 'Race effects on employee engagement-turnover intention relationship', Journal of Leadership and Organizational Studies, 11(2), pp. 78-88. Available at: http://www.emeraldinsight.com (Accessed: 18 Oct 2009).

Mabey, C. \& Robertson, I (1990) 'HRM practices and employee commitment: Possibilities, pitfalls and paradoxes', British Journal of Management, 1, pp. 147-157. Available at: http://www.interscience.wiley.com (Accessed: 15 Oct 2009).

Marcum, J (2000) 'Out with motivation, in with engagement', Employee Relations, 18(4), pp. 57-60. Available at: http://www.interscience.wiley.com (Accessed: 13 Oct 2008).

May, D. R (2003) 'Fostering the human spirit at work: Toward an understanding of the influences on employees' experienced meaningfulness at work', Personnel Psychology, 46, pp.51-71, Available at: www.interscience.wiley.com (Accessed: 18 Oct 2009).

May, D. R. \& Schwoerer, C. E (1994) 'Employee health by design: Using employee involvement teams in ergonomic job redesign', Personnel Psychology, 47, pp.861-876. Available at: http://www.emeraldinsight.com (Accessed: 18 Oct 2009).

Oakley, J.L (2004) 'linking organizational characteristics to employee attitudes and behaviour', Performance Management and Measurement, Available at: http://search.ebscohost.com (Accessed: 29 Oct 2009).

Pech, R. \& Slade, B (2006) 'Employee disengagement: Is there evidence of a growing problem?', Hanbook of Business Strategy, 7, pp. 21-25. Available at: http://search.ebscohost.com (3 Oct 2009).

Pfeffer, J (1998) The human equation: building profits by putting people first. Boston: Harvard Business School Press.

Renwick, D (2002) 'Line manager involvement in careers', Career Development International, 7(7), pp. 407-414. Available at: http://www.emeraldinsight.com (Accessed: 14 Oct 2009).

Rothbard, N. \& Edwards, J.(2003) 'Investment in work and family roles: A test of identity and utilitarian motives', Personnel Psychology, 56, pp. 699-730. Available at: http://www.emeraldinsight.com (Accessed: 12 Oct 2009). 
Schaufeli, W. \& Bakker, A (2002) 'The measurement of engagement and burnout and a confirmative analytic approach', Journal of Happiness Studies, 3, pp. 71-92. Available at: http://search.ebscohost.com (Accessed: 4 Oct 2009).

Schaufeli, W. B. \& Rhenen, W (2008) 'Workaholism, burnout and work engagement: three different kinds of employee well being', Applied Psychology, 57, pp. 173-203. Available at: http://search.ebscohost.com (Accessed: 13 Oct 2009).

Spreitzer, G. M (1995) 'psychological empowerment in the work place: dimensions, measurement, and validation', Academy of management Journal, 38, pp. 1442-1465. Available at: http://search.ebscohost.com (Accessed: 7 Oct 2009).

Spreitzer, G. M. \& Nason, S. W (1997) 'A dimensional analysis of the relationship between psychological empowerment and effectiveness, satisfaction, and strain', Journal of Management, 23, pp.679-704. Available at: http://search.ebscohost.com (Accessed: 12 Oct 2009).

Thomas, K. W. \& Velthouse, B (1990) 'Cognitive elements of empowerment: An interpretive model of intrinsic task motivation', Academy of Management Review, 15, pp. 666-681. Available at: http://serach.ebscohost.com (Accessed: 15 Oct 2009).

Vallerand, R \& Houlfort, N (2003) Passion at work: Toward a new conceptualization. Greenwich: CT

\section{Appendix A:}

\section{Personal reflective statement}

When I was given a research proposal, I first thought about Employee Engagement and the various HR practices, which could boost engagement levels and processes within an organization. Since writing this report, I have learnt about the deeper and wider perspective of the term engagement and its significance in terms of managers' interventions and connections with human resources processes and procedures.

When I decided to take on the research topic I knew I was going to study an area associated with "Employee Engagement" issues and practices. From the various ideas, which I had in my mind, one was to how can line managers enhance engagement processes within the Barclays bank in order to improve organizational performance. In fact, that idea certainly captivated my interest to identify the theories and practices of HRM that add value to increase engagement in order to accomplish better financial outcomes within an organization. Because I worked in Barclays bank for six months, before coming to UK for higher studies, what I found there that the employees or individuals were not involved or engaged within their job roles. These gestures of employees and managers really arouse my interest somehow to find the variables, which hampered engagement processes within the bank. In fact, the amount of information collected was aligned with the associated factors in the topic addressed during the questionnaire analysis and management interview analysis. Furthermore, 
this management report has facilitated me to improve my knowledge and gain an appreciation from the HR department in order to bring about a change with a bank. Consequently, it could be exhibited that I am more conscious of the extent of addressing the issue of employee engagement. However, due to the busy schedule of line managers within a bank, it was bit difficult to explore detailed findings on the question otherwise data analysis and findings section could have been discovered more. Nevertheless, I presumed that all the line managers were realistic and truthful in terms of answering the questions in semi structured interviews.

This report enables me to focus on the key factors of engagement, which could affect the workforce in order to ameliorate the organizational performance. In fact, the report still needs to identify some more factors to intensify engagement and its driving forces. However, employee engagement is quite a complex term and there could be so many themes and issues, which could be included. Besides, I acknowledged the literature that could be useful and highlighted what I evaluated to be the most authentic and relevant information.

The search for contemporary literature review and further reading to make certain that I had considered all the perspectives actually delayed the project from its original schedule. Similarly, I had to go to Pakistan in order to do my data collection and findings, so this also made me a bit late to complete the whole project. However, the vast reading around the argument helped me to get back on track to finish a project two weeks before the hand-in date. Thus, in the future I would make sure that the deadlines need to be set properly and all the activities for instance, literature review, findings, etc need to be done on time.

The data findings and analysis part was completely quickly and efficiently. In fact, all the respondents including employees and the line managers were quite educated, so I did not find any difficulty in clarifying some of the complex terms, which were addressed in the interview analysis part. However, the whole exercise was too time consuming and due to the busy schedule of the managers, I assume that the information might have not been fully explored. Nevertheless, the findings I gathered in the primary research are significantly consistent with the literature review.

I were given an opportunity to redo the dissertation, I would have conducted some more interviews of other managers in order to gain in-depth and tacit knowledge of the situation within an organization. Likewise, with regards to the interviews, I perceive that I still have to learn about interviewing skills and tactics particularly when you simply a postgraduate student and interviewing senior management. In addition, I would also like to undertake unstructured interviews rather than semi structured interviews from line managers and this would allow me to get a better reality and understanding of the factors, which will enhance engagement processes to accomplish organizational objectives and this strategy would also enable line managers to use those variables as a benchmark for the future implications.

Generally speaking, this has been a very great and useful learning for me not only in terms of applying theory in to practice but also in terms of awareness of current issues and problems in implementing engagement processes within a company. In fact, this has been a useful and 


\section{Macrothink}

fantastic learning for me and all the academic reading, which I did in doing my dissertation, really boost my knowledge in to the exciting factors of employee engagement.

In addition, this new learning, which I have not done before also, taught me how to critically evaluate the data and think rationally and practically to deal with issues and form new ideas and opinions. Likewise, I also think that I have build on my English vocabulary and now I am much more aware of the terms and jargons of HRM and can easily use it in my job role to impress my senior management. Consequently, I can say that this has been a tremendous learning experience for me.

\section{Copyright Disclaimer}

Copyright for this article is retained by the author(s), with first publication rights granted to the journal.

This is an open-access article distributed under the terms and conditions of the Creative Commons Attribution license (http://creativecommons.org/licenses/by/3.0/). 